\title{
ALINHAMENTO ORGANIZACIONAL PARA A IMPLEMENTAÇÃO DE ESTRATÉGIAS
}

\section{ORGANIZATIONALALIGNMENT FOR IMPLEMENTING STRATEGIES}

\author{
Luís Alberto Monteiro de Barros \\ Universidade Federal do Pará - Belém - PA \\ labarros@ufpa.br
}

Recebido em 25.05.2018. Aprovado em 17.02.2019

Avaliado pelo sistema double blind review

\section{Antonio Max Martins dos Santos}

Universidade Federal do Pará - Belém - PA

makssaints@gmail.com

\begin{abstract}
Resumo
Muitas estratégias organizacionais fracassam por dificuldades na execução, havendo ampla produção bibliográfica que associa a eficácia da implementação estratégica à gestão do alinhamento organizacional. Essa base teórica, entretanto, apresenta-se esparsa entre diferentes abordagens e insuficientemente organizada para orientar a aplicação prática e bem-sucedida desse conhecimento durante a execução das estratégias. $O$ objetivo da presente pesquisa, portanto, consistiu na proposição de um modelo teórico de pesquisa que consolidasse indicadores de como o alinhamento estratégico contribui para a eficácia da implementação de estratégias organizacionais, arranjado em categorias de recomendações da literatura, a fim de viabilizar estudos acadêmicos futuros. Trata-se de uma investigação exploratória, bibliográfica e bibliométrica, que aplicou método de revisão sistemática da literatura, com a utilização de técnicas qualitativas e quantitativas de análise e síntese do material coletado a partir da base de dados do Portal de Periódicos da CAPES, referentes a publicações catalogadas no período de 1990 a 2017. Os trabalhos realizados permitiram constatar que há diversas abordagens teóricas do tema alinhamento estratégico, que apresentam divergências, mas também convergências em seus escopos, estas especialmente nos textos das áreas da tecnologia da informação e da administração, as quais sugerem que 0 alinhamento consiste em um meio através do qual se pode alcançar a eficácia da implementação da estratégia, e foram a base para a elaboração do inédito modelo teórico proposto ao final, que elenca indicadores de eficácia em quatro dimensões de alinhamento: recursos e capacidades; ações; controles; e desenho organizacional
\end{abstract}

Palavras-chaves: Alinhamento estratégico. Implementação da estratégia. Eficácia. Revisão Sistemática da Literatura. Modelo Teórico.

\begin{abstract}
Many organizational strategies fail because of difficulties that emerge in the execution phase, while there is an extensive literature that associates strategic implementation effectiveness to the management of organizational alignment. However, this theoretical foundation finds itself widely spread and disorganized lost among different approaches, which hinders the practical and successful orientation of its application for strategy execution. With the intent of enabling future academic studies, the present work proposed to build a
\end{abstract}


research theoretical model capable of consolidating indicators on how strategic alignment promotes organizational strategies implementation's effectiveness, arranged in categories of recommendations obtained from literature. It consists of an exploratory, bibliographical and bibliometrics investigation, which applied a method of systematic literature review, using qualitative and quantitative techniques of analysis and synthesis of the material collected from the CAPES Portal de Periódicos' database, referring to publications compiled from 1990 to 2017. The work carried out showed that there are several theoretical approaches to the subject of strategic alignment, which present divergences but also convergences in their scopes, especially in the texts from the information technology and administration areas, which suggest that alignment consists of a means through which strategy implementation effectiveness can be achieved and were the basis for the elaboration of the unique theoretical model proposed at the end of this study, which lists effectiveness indicators in four dimensions of alignment: resources and capabilities; initiatives; controls; and organizational design.

Keywords: Strategic Alignment. Strategy Implementation. Effectiveness. Systematic Literature Review. Theoretical Model.

\section{Introdução}

Implementar uma estratégia organizacional significa colocar essa estratégia para funcionar, após a sua formulação (HEIDE; GRONHAUG; JOHANNESSEN, 2002; HÅKONSSON et al, 2012; OMONDI; OMBUI; MUNGATU, 2013) e envolve a conversão dos objetivos estratégicos em desempenho, através do alinhamento organizacional (PELLA et al, 2013), por vezes nomeado de alinhamento estratégico.

Muitas estratégias organizacionais fracassam não por problemas na formulação da estratégia, mas sim por dificuldades na sua implementação (AHMADI, et al, 2012), a qual envolve obstáculos e problemas complexos (PELLA et al, 2013). Assim, mesmo estratégias melhor formuladas podem não produzir 0 desempenho esperado pela organização se não forem corretamente implementadas (OMONDI; OMBUl; MUNGATU, 2013)

A eficácia da implementação das estratégias, nesse contexto, aproxima-se conceitualmente do modelo do objetivo apresentado por Cameron (1986), similar ao modelo conceitual mais comum das abordagens universais de eficácia organizacional, segundo o qual ser eficaz significa alcançar o objetivo da organização (COOPER; ARGYRIS, 2003). Partindo do pressuposto de que a estratégia formula objetivos (GĘBCZYŃSKA, 2016) e a implementação persegue o alcance desses objetivos (HERHAUSEN; EGGER; ORAL, 2014), então a implementação eficaz da estratégia passa necessariamente por atingir esses objetivos (HERHAUSEN; EGGER; ORAL, 2014).

Nessa linha de raciocínio, quando a base teórica do alinhamento estratégico organizacional apresenta alternativamente os termos eficácia da implementação (HERHAUSEN; EGGER; ORAL, 2014; KARIM; ARIFUZ-ZAMAN, 2013; OMONDI; OMBUI; MUNGATU, 2013; SRIVASTAVA; SUSHIL, 2015), execução bemsucedida (HERHAUSEN; EGGER; ORAL, 2014; KAPLAN; NORTON, 1996; RAYMOND; CROTEAU, 2009; SRIVASTAVA; SUSHIL, 2015), implementação de sucesso (CHAN; SABHERWAL; THATCHER, 2006; CHAO; CHANDRA, 2012; HERHAUSEN; EGGER; ORAL, 2014; STROHHECKER, 2016), ou outras designações na mesma direção, como implementação apropriada (HÅKONSSON et al, 2012), para se referir ao desempenho da estratégia, admite-se que a implementação eficaz é aquela que conduz ao alcance dos objetivos da estratégia, quaisquer que sejam esses objetivos, o que pode recepcionar toda a complexidade e diversidade composta por outras abordagens de eficácia organizacional.

A revelação de Darmin Ahmad Pella e outros (2013) citada acima, de que o alinhamento da organização contribui para a conversão dos seus objetivos estratégicos em desempenho, associada ao disposto de que a eficácia da implementação da estratégia pode ser avaliada com base no alcance dos seus objetivos, entretanto, não se apresenta suficientemente organizada para orientar a aplicação prática e bem-sucedida desse conhecimento durante a execução das estratégias, emergindo a seguinte questão: Como 0 alinhamento estratégico contribui para a eficácia da implementação de estratégias organizacionais, segundo 


\section{a base teórica?}

Sabe-se ainda que há diferentes e esparsas definições do termo alinhamento estratégico na literatura, de forma que se considera relevante identificar e analisar as variadas abordagens do termo, para que se responda: Há como categorizar as recomendações da base teórica acerca de aspectos a alinhar para que se obtenha a eficácia da implementação de estratégias organizacionais?

O objetivo desta pesquisa consistiu, portanto, na proposição de um modelo teórico de pesquisa que consolidasse diferentes indicadores de como o alinhamento estratégico contribui para a eficácia da implementação de estratégias organizacionais, arranjado em categorias de recomendações da literatura, a fim de testar o modelo no campo em estudos acadêmicos futuros.

\section{Alinhamentos estratégicos}

0 advento do termo alinhamento estratégico encontra-se na origem, senão na essência, do pensamento estratégico organizacional (meados do século passado), quando a solução para 0 , naquela ocasião denominado problema estratégico (a discrepância entre os produtos da organização, por um lado, e a demanda do mercado, pelo outro) era o planejamento estratégico, então conceituado como uma análise racional das oportunidades oferecidas pelo ambiente, dos pontos fortes e fracos da empresa e um ajuste (estratégia), do inglês fit, entre esses dois grupos de aspectos externos e internos que melhor satisfizessem os objetivos da organização (ANSOFF, I. H.; DECLERCK, R. P.; HAYES, R. L, 1976).

O termo fit era utilizado frequentemente para especificar relações estratégicas de gestão, quando era então invocado no sentido dessa conceituação geral de ajuste ou adequação, denominada alternadamente também de contingência, congruência, coerência, consistência, entre outros sinônimos (VENKATRAMAN, 1988).

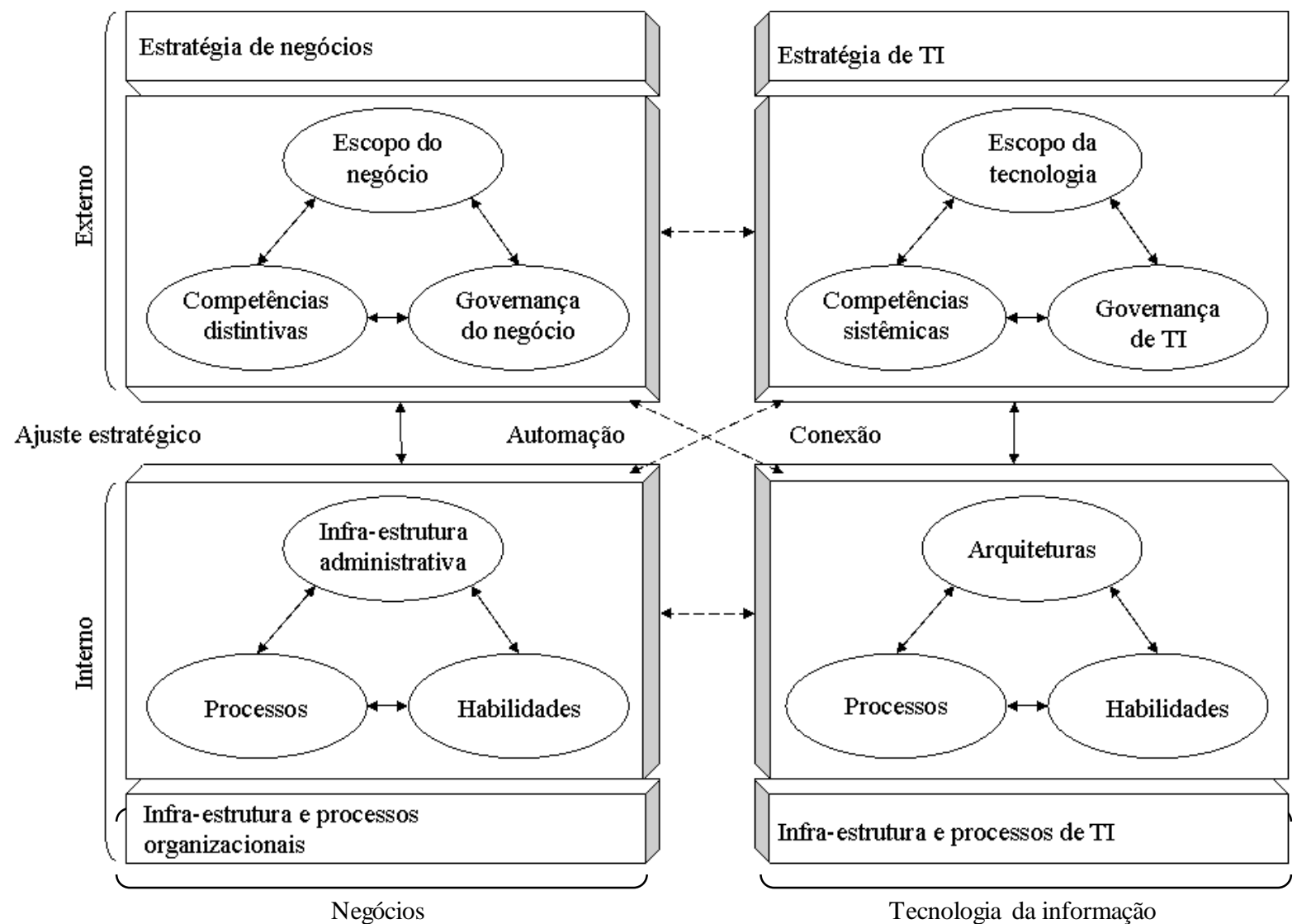

Figura 1 - Modelo de alinhamento estratégico de Henderson e Venkatraman

Fonte: Henderson e Venkatraman (1993, p. 8) - tradução dos autores 
Nessa conjuntura, o termo alinhamento aparecia associado a temas como (VENKATRAMAN, N.; CAMILLUS, J. C., 1984): interdependência entre estratégias de várias organizações; mecanismos administrativos e organizacionais em linha com a estratégia; moderação entre o ponto de vista determinístico e o de cautela gerencial; gerenciamento estratégico envolvendo a formulação e a implementação, cobrindo decisões ambientais e organizacionais; e interdependência entre organização e ambiente.

No início da década de 1990, envoltos em um contexto da tecnologia da informação (TI), Henderson e Venkatraman (1993) escreveram que o conceito de alinhamento estratégico se baseava nos pressupostos de que: o desempenho econômico está diretamente relacionado à habilidade do administrador de criar um ajuste estratégico entre a posição da organização e a arena competitiva de produto-mercado, mais a montagem de uma estrutura administrativa apropriada para apoiar a sua execução; bem como de que este ajuste estratégico é inerentemente dinâmico, de tal forma que as escolhas efetuadas por uma determinada organização empresarial poderão suscitar ações de organizações rivais imitadoras, as quais exigem a respectiva resposta.

O modelo de alinhamento estratégico proposto por Henderson e Venkatraman (Figura 1), portanto, foi definido por eles em quatro domínios fundamentais de escolha estratégica: estratégia de negócios; estratégia de Tl; infraestrutura e processos organizacionais; e infraestrutura e processos de e $\mathrm{Tl}$, cada um com suas próprias dimensões subjacentes.

Partindo destes pressupostos, Henderson e Venkatraman (1993) definiram o alinhamento estratégico como possuindo dois pilares de sustentação, ou seja, o ajuste estratégico e a integração funcional, de forma que o primeiro pilar se refere às ações e reações da organização, em relação aos seus domínios interno e externo, e o segundo corresponde à necessidade de se integrar a estratégia de TI à estratégia de negócios da organização empresarial (integração estratégica); e de se conectar a infraestrutura e os processos organizacionais com a infraestrutura e os processos dos sistemas de informação (integração operacional).

No mesmo ano, Luftman, Lewis e Oldach (1993) escreveram que o alinhamento estratégico reflete a visão de que o sucesso do negócio depende da conexão entre: a estratégia de negócios; a estratégia de Tl; a infraestrutura e processos organizacionais; e a infraestrutura e processos de TI, indo ao encontro do definido por Henderson e Venkatraman (1993). Naquela ocasião, Luftman, Lewis e Oldach afirmaram que a utilização eficaz e eficiente da TI exigia o alinhamento das estratégias de TI com as estratégias de negócios, algo que (segundo eles) não havia sido feito com sucesso até então, mediante abordagens tradicionais que trabalhavam isoladamente essas áreas. Segundo eles, era necessário construir um conjunto de processos de negócios que refletissem a interdependência entre a estratégia da organização e as capacidades da TI.

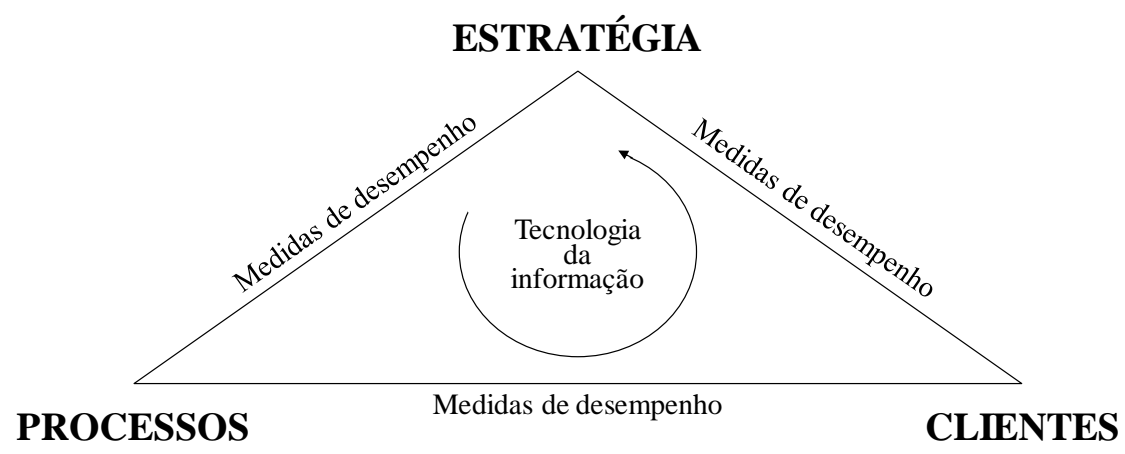

Figura 2 - Modelo de alinhamento estratégico de Lockamy III e Smith

Fonte: Lockamy III e Smith (1997, p. 142) - tradução dos autores

Quatro anos depois, Lockamy III e Smith (1997) utilizaram o termo e um modelo de alinhamento estratégico (Figura 2) para se referir à conexão entre a estratégia da organização, seus processos de negócios, e os requisitos dos seus clientes, para buscar eficácia na reengenharia dos processos de negócios (aumentar a 
chance de sucesso dos programas de reengenharia, que à época possuíam uma taxa de falha entre $60 \% \mathrm{e}$ $80 \%$ ) e então obter vantagem competitiva.

Na mesma época, Chan e outros (1997) definiram alinhamento estratégico de sistemas de informação como o ajuste entre a orientação estratégica dos negócios e a orientação estratégica dos sistemas de informação (SI), constructos relacionados com a eficácia dos SI e com o desempenho do negócio, bem como propuseram naquela ocasião novas abordagens de análise da estratégia realizada de SI e do alinhamento estratégico de Sl.

Nos quatro trabalhos até aqui citados percebe-se textualmente a preocupação com o sucesso, a eficácia, a eficiência e o desempenho do negócio, como justificativa para a aplicação do por eles chamado alinhamento estratégico.

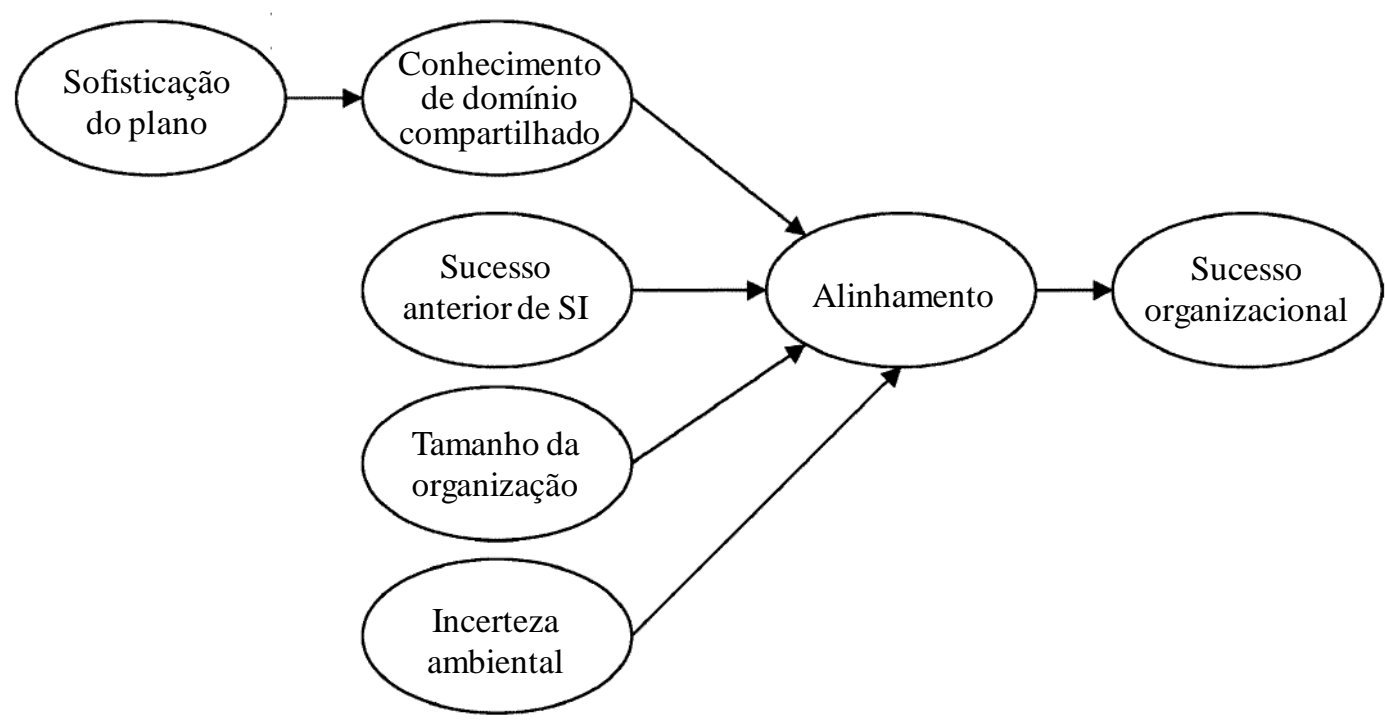

Figura 3 - Modelo teórico de alinhamento estratégico

Fonte: Adaptado de Chan, Sabherwal e Thatcher (2006, p. 28)

No início da década seguinte, outros acadêmicos utilizaram o termo alinhamento estratégico para designar algo similar, qual seja, o alinhamento entre a estratégia de SI e a estratégia de negócios (SABHERWAL; CHAN, 2001) ou o grau em que a missão, os objetivos e os planos contidos nas estratégias de negócios são compartilhados e apoiados pela estratégia de SI (CHAN; SABHERWAL; THATCHER, 2006). Em certa consonância com o citado trabalho de Henderson e Venkatraman (1993), assim como com o de Luftman, Lewis e Oldach (1993), está o fato de que esses trabalhos mais recentes defendem que o alinhamento estratégico pode melhorar a performance em alguns tipos de organizações, estas caracterizadas como prospectoras e analisadoras, mas não naquelas caracterizadas como defensoras, em uma referência ao trabalho de Miles e outros (1978)1.

Em um contexto mais próximo da administração do que da TI, de meados daquela época, por outro lado, Wunder (2005) apresentou o termo alinhamento estratégico associado à integração entre unidades estratégicas de negócios (UENs) de corporações multinacionais (CMNs). Nesse contexto, Wunder defende que existem dois tipos de alinhamento: o vertical e o horizontal (Figura 4). 


\section{Luís Alberto Monteiro de Barros e Antonio Max Martins dos Santos}
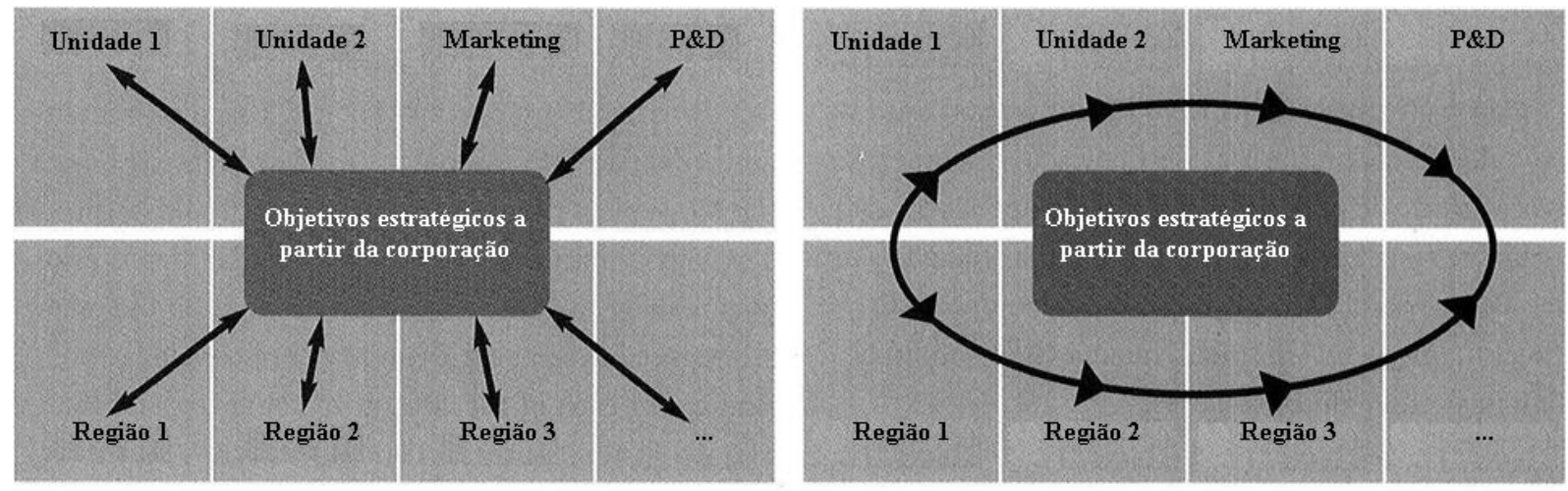

Figura 4 - Estrutura para o processo do alinhamento vertical e horizontal

Fonte: Wunder (2005, p. 39) - tradução dos autores

O alinhamento vertical, segundo Wunder, refere-se à busca por assegurar que todas as ações nos níveis mais baixos da organização, a partir das unidades estratégicas de negócios, estão acontecendo na mesma direção, juntamente com a corporação, e o alinhamento horizontal compreende os trabalhos de resolução de conflitos entre as metas das unidades de mesmo nível organizacional.

A despeito das nítidas diferenças entre as abordagens anteriores (mais próximas do universo da tecnologia da informação) e a ideia de Wunder (com um enfoque mais corporativo), esta comunga com as primeiras naquilo que ele sinaliza ser o alvo do alinhamento estratégico: o sucesso empresarial. Wunder dizia naquela época ser difícil encontrar aplicações dos processos de alinhamento estratégico entre UENs, funções ou serviços globais e regiões inseridas nas muitas vezes complexas CMNs, mas que a matriz corporativa deve garantir que suas UENs sejam coletivamente mais bem-sucedidas do que se estivessem agindo de forma individual.

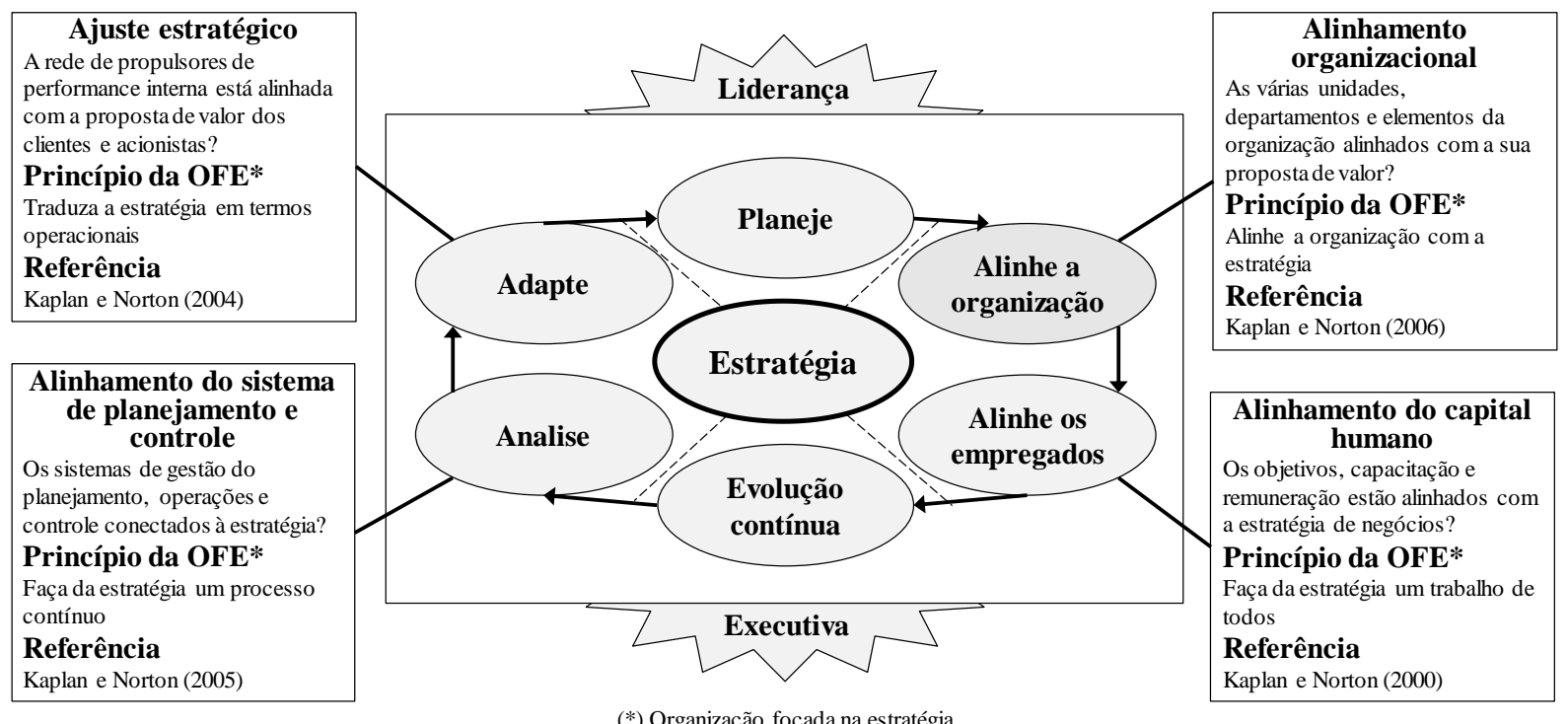

Figura 5 - Modelo do alinhamento estratégico total

Fonte: Adaptado de Kaplan e Norton (2006)

No mesmo período, Kaplan e Norton (2006) introduziram o conceito de alinhamento estratégico total, partindo da ideia central de que a estratégia da organização é o centro do seu sistema de gestão. 
Adicionalmente, Kaplan e Norton afirmam que uma forte liderança do executivo é condição necessária para o sucesso da implementação da estratégia, com o gerenciamento de suas mudanças, e acrescentam que 0 alinhamento consiste em uma parte específica do processo de gerenciamento, dado que a implementação da estratégia requer um alto nível de integração e trabalho de equipe entre os processos e unidades organizacionais.

Uma vez claramente definida a estratégia da organização, afirmaram Kaplan e Norton, todos os componentes do processo de gerenciamento são direcionados para criar o alinhamento estratégico total, que é composto por quatro elementos: 0 ajuste estratégico; 0 alinhamento organizacional; 0 alinhamento do capital humano; e o alinhamento do sistema de planejamento e controle (Figura 5).

Kaplan e Norton (2006) também utilizam a palavra sucesso para se referir ao benefício obtido através do alinhamento estratégico, no caso o sucesso da implementação da estratégia. Disseram eles que a implementação da estratégia não é fruto do acaso, mas sim o resultado de um trabalho consciente, que combina tanto os processos de liderança como os de gerenciamento para: delinear e avaliar a estratégia; alinhar as unidades organizacionais internas e externas; alinhar os colaboradores com a estratégia através de motivação; e para alinhar os processos de gerenciamento, relatórios e reuniões de revisão existentes com a execução, monitoramento e adaptação da estratégia.

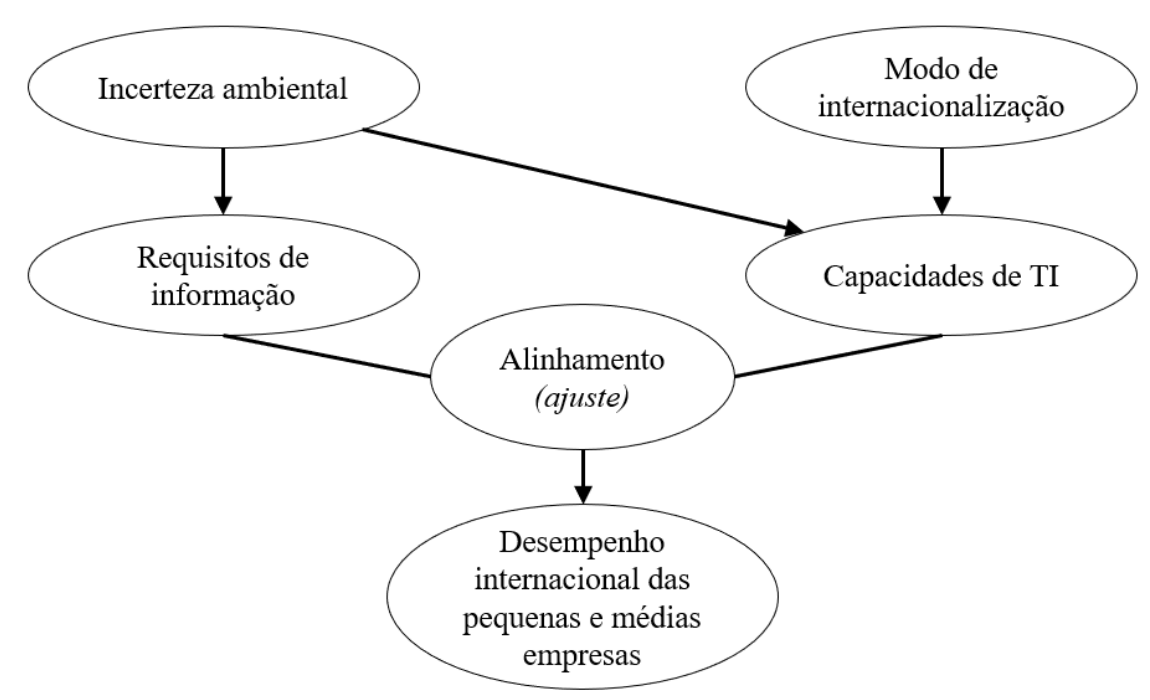

Figura 6 - Modelo teórico de alinhamento de Dutot, Bergeron e Raymond Fonte: Adaptado de Dutot, Bergeron e Raymond (2014)

Os professores François Bergeron e Louis Raymond, são alguns dos autores que mais publicaram em revistas científicas acerca de alinhamento estratégico. Bergeron e Raymond, com Suzanne Rivard (2004) definem alinhamento estratégico como um conceito relacionado a como as organizações podem traduzir a implantação da $\mathrm{TI}$ em aumentos reais de desempenho e apresentam estudo que examinou o impacto do processo entre estratégia e estrutura de negócios, estratégia e estrutura de TI no desempenho do negócio de pequenas e médias empresas.

Segundo Bergeron e Raymond (2008), a noção de alinhamento estratégico decorre da pesquisa acerca da teoria da organizacional e da gestão estratégica, cuja proposição fundamental é a de que o desempenho organizacional é consequência de uma coerência (ajuste) entre fatores como estratégia, estrutura e tecnologia. 


\begin{tabular}{|l|l|l|}
\hline \multicolumn{1}{|c|}{ Publicação } & \multicolumn{1}{|c|}{ Principais aspectos a alinhar } & \multicolumn{1}{c|}{$\begin{array}{c}\text { Objetivos dos } \\
\text { alinhamentos }\end{array}$} \\
\hline $\begin{array}{l}\text { Henderson e } \\
\text { (1993) }\end{array}$ & $\begin{array}{l}\text { a) Estratégia de TI com a estratégia de } \\
\text { negócios; e } \\
\text { b) Infraestrutura e os processos organizacionais } \\
\text { com a infraestrutura e os processos dos SI. }\end{array}$ & $\begin{array}{l}\text { a) Desempenho da } \\
\text { organização em termos } \\
\text { econômicos. }\end{array}$ \\
\hline $\begin{array}{l}\text { Luftman, Lewis e } \\
\text { Oldach (1993) }\end{array}$ & $\begin{array}{l}\text { a) A estratégia de negócios com a estratégia de } \\
\text { Tl; e } \\
\text { b) Infraestrutura e processos organizacionais } \\
\text { com a infraestrutura e processos de TI. }\end{array}$ & $\begin{array}{l}\text { a) Desempenho (sucesso) } \\
\text { do negócio da } \\
\text { organização. }\end{array}$ \\
\hline $\begin{array}{l}\text { Chan e outros } \\
\text { (1997) }\end{array}$ & $\begin{array}{l}\text { a) Orientação estratégica dos negócios com a } \\
\text { orientação estratégica dos Sl. }\end{array}$ & $\begin{array}{l}\text { a) Desempenho da } \\
\text { organização }\end{array}$ \\
\hline $\begin{array}{l}\text { Sabherwal e Chan } \\
\text { (2001) }\end{array}$ & $\begin{array}{l}\text { a) Estratégia de negócios com a estratégia de } \\
\text { Sl. }\end{array}$ & $\begin{array}{l}\text { a) Desempenho (sucesso) } \\
\text { do negócio }\end{array}$ \\
\hline $\begin{array}{l}\text { Bergeron, Raymond } \\
\text { e Rivard (2004) }\end{array}$ & $\begin{array}{l}\text { a) Estratégia de negócios, estrutura de } \\
\text { negócios, estratégia de TI e estrutura de TI. }\end{array}$ & $\begin{array}{l}\text { a) Desempenho do } \\
\text { negócio }\end{array}$ \\
\hline $\begin{array}{l}\text { Dutot, Bergeron e } \\
\text { Raymond (2014) }\end{array}$ & $\begin{array}{l}\text { a) Alinhamento de TI com a estratégia de } \\
\text { negócios. }\end{array}$ & $\begin{array}{l}\text { a) Desempenho } \\
\text { organizacional } \\
\text { (internacional, de } \\
\text { pequenas e médias } \\
\text { empresas) }\end{array}$ \\
\hline $\begin{array}{l}\text { Abib e Hoppen } \\
\text { (2015). }\end{array}$ & $\begin{array}{l}\text { a) Objetivos entre o negócio e a Tl; e } \\
\text { b) Missão, objetivos e planos da estratégia de } \\
\text { negócios e estratégia de TI. }\end{array}$ & $\begin{array}{l}\text { a) Sucesso na } \\
\text { implementação de } \\
\text { ferramenta estratégica de } \\
\text { TI. }\end{array}$ \\
\hline
\end{tabular}

Quadro 1 - Abordagens de alinhamento estratégico que vinculam negócios com tecnologia da informação Fonte: Os autores deste estudo

Com Vincent Dutot, na década seguinte, Bergeron e Raymond utilizam o termo alinhamento estratégico de TI para designar um tipo específico de ajuste necessário, que consiste basicamente no alinhamento entre TI e a estratégia de negócios da organização (DUTOT; BERGERON; RAYMOND, 2014). Segundo os resultados dos estudos destes, organizações internacionais (pequenas e médias empresas, no caso) que preencherem seus requisitos de informação, implementando os recursos de TI apropriados, tendem a ter melhor desempenho na internacionalização do que aquelas que não trabalharem esse tipo de alinhamento (p. 679).

No Brasil, alguns dos acadêmicos que mais abordaram o tema alinhamento estratégico foram Prieto e Carvalho, tendo o seu artigo mais recente tratado do alinhamento estratégico vertical, definido por elas como uma situação de coerência em que os níveis hierárquicos inferiores da organização estabelecem estratégias, objetivos e planos que viabilizam a concretização de uma estratégia elaborada em um nível superior, favorecendo o sucesso de sua implementação (PRIETO; CARVALHO, 2016).

Nesse mesmo contexto da implementação de estratégias, Monteiro de Barros (2007) apresentou estudos feitos no Brasil segundo os quais o adequado alinhamento da estratégia organizacional com os recursos necessários, as ações e os controles para implementá-la, bem como com o desenho da organização, aumentam as chances de eficácia da implementação da estratégia, denominando esse constructo de alinhamento estratégico 


\begin{tabular}{|c|c|c|}
\hline Publicação & Principais aspectos a alinhar & Objetivos dos alinhamentos \\
\hline $\begin{array}{l}\text { Lockamy III e Smith } \\
\text { (1997) }\end{array}$ & $\begin{array}{l}\text { a) Estratégia da organização com seus } \\
\text { processos de negócios, e com os requisitos } \\
\text { dos seus clientes. }\end{array}$ & $\begin{array}{l}\text { a) Desempenho (sucesso) } \\
\text { dos programas de } \\
\text { reengenharia da } \\
\text { organização; e } \\
\text { b) Vantagem competitiva da } \\
\text { organização. }\end{array}$ \\
\hline Wunder (2005) & $\begin{array}{l}\text { a) Unidades estratégicas de negócios; } \\
\text { b) Funções ou serviços globais; e } \\
\text { c) Regiões. }\end{array}$ & a) Sucesso organizacional \\
\hline $\begin{array}{l}\text { Kaplan e Norton } \\
(2006)\end{array}$ & $\begin{array}{l}\text { a) Unidades organizacionais internas e } \\
\text { externas; } \\
\text { b) Colaboradores com a estratégia; } \\
\text { c) Processos de gerenciamento, relatórios e } \\
\text { reuniões de revisão existentes com a } \\
\text { execução, monitoramento e adaptação da } \\
\text { estratégia. }\end{array}$ & $\begin{array}{l}\text { a) Sucesso da } \\
\text { implementação da } \\
\text { estratégia }\end{array}$ \\
\hline $\begin{array}{l}\text { Bergeron e } \\
\text { Raymond (2008) }\end{array}$ & a) Estratégia, estrutura e tecnologia. & $\begin{array}{l}\text { a) Desempenho } \\
\text { organizacional }\end{array}$ \\
\hline $\begin{array}{l}\text { Prieto e Carvalho } \\
\text { (2016) }\end{array}$ & $\begin{array}{l}\text { a) Estratégias, objetivos e planos das } \\
\text { estratégias inferiores com as estratégias de } \\
\text { nível superior. }\end{array}$ & $\begin{array}{l}\text { a) Sucesso na } \\
\text { implementação das } \\
\text { estratégias. }\end{array}$ \\
\hline $\begin{array}{l}\text { Monteiro de Barros } \\
\text { (2007) }\end{array}$ & $\begin{array}{l}\text { a) Estratégia e os recursos e capacidades } \\
\text { necessários para implementá-la; } \\
\text { b) Estratégia e as ações para implementá-la; } \\
\text { c) Estratégia e os controles para implementá- } \\
\text { la; e } \\
\text { d) Estratégia e o desenho organizacional. }\end{array}$ & $\begin{array}{l}\text { a) Eficácia da } \\
\text { implementação da } \\
\text { estratégia }\end{array}$ \\
\hline
\end{tabular}

Quadro 2 - Abordagens organizacionais de alinhamento estratégico

Fonte: Os autores deste estudo

Gustavo Abib se apresenta também como um estudioso do tema no ambiente brasileiro, e seu último de vários trabalhos na área, com Hoppen, sugere que o alinhamento estratégico pode contribuir para o sucesso na implementação de ferramenta estratégica de TI, e comunga da ideia de que ele consiste em um ajustamento de objetivos entre o negócio e a TI, ou ainda no grau no qual a missão, os objetivos e os planos contidos na estratégia de negócios da empresa suportam e são suportados pela estratégia de TI (ABIB; HOPPEN, 2015).

Outras abordagens fora do contexto organizacional também podem ser encontradas na literatura acadêmica, tais como: 0 trabalho de Ohashi Kazuo, que estudou o alinhamento estratégico de células parenquimatosas para o estabelecimento de terapia para doenças do fígado e diabetes mellitus (KAZUO, 2013); o estudo de Susan Brown, que sugere alinhar aprendizados e padrões essenciais do sistema de currículo, avaliação e relatórios da cidade de Queensland na Austrália, para melhorar o processo de ensino e aprendizado na educação formal (BROWN, 2008); ou ainda o texto de Jesus Alcoba, que conceitua alinhamento estratégico como a coerência entre objetivos de aprendizado e métodos de ensino, por um lado, e os objetivos educacionais da instituição, por outro, sugerindo que esse alinhamento pode reforçar a identidade de uma instituição de ensino superior (IES) e diferenciá-la de outras, no mercado (ALCOBA, 2014). 


\begin{tabular}{|l|l|l|}
\hline \multicolumn{1}{|c|}{ Publicação } & \multicolumn{1}{|c|}{ Principais aspectos a alinhar } & Objetivos dos alinhamentos \\
\hline Kazuo (2013) & a) Células parenquimatosas in vivo. & $\begin{array}{l}\text { a) Estabelecimento de } \\
\text { terapia para doenças do } \\
\text { fígado e diabetes } \\
\text { mellitus. }\end{array}$ \\
\hline Brown (2008) & $\begin{array}{l}\text { a) Aprendizados e padrões essenciais do } \\
\text { sistema de currículo, avaliação e relatórios. }\end{array}$ & $\begin{array}{l}\text { a) Sucesso no processo de } \\
\text { ensino e aprendizado. }\end{array}$ \\
\hline Alcoba (2014) & $\begin{array}{l}\text { a) Objetivos de aprendizado e métodos de } \\
\text { ensino com os objetivos educacionais da } \\
\text { instituição de ensino. }\end{array}$ & $\begin{array}{l}\text { a) Reforçar a identidade de } \\
\text { uma IES e diferenciá-la } \\
\text { de outras, nesse } \\
\text { mercado. }\end{array}$ \\
\hline
\end{tabular}

Quadro 3 - Abordagens de alinhamento estratégico não organizacionais Fonte: Os autores deste estudo

\section{Método}

Tratou-se a presente pesquisa de uma investigação: exploratória, por ter sido realizada em área na qual há pouco conhecimento acumulado e sistematizado; bibliográfica, tendo em vista consistir em um estudo sistematizado desenvolvido com base em material publicado em livros, revistas e outros trabalhos científicos, conforme classificação de Vergara (2016); e bibliométrica, por também ter aplicado métodos matemáticos e estatísticos à literatura científica e aos autores que a produziram, com o objetivo de estudar e analisar a atividade acadêmica, nos termos definidos por Senra e Lourenço (2016).

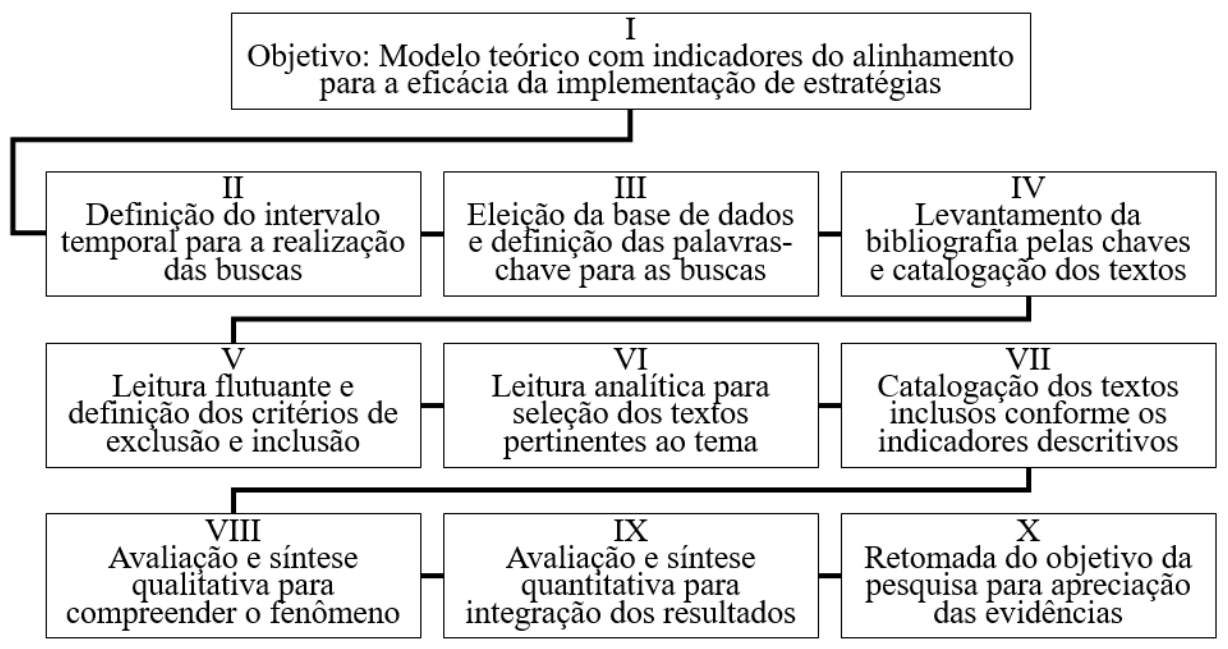

Figura 7 - Revisão sistemática da literatura realizada na pesquisa

Fonte: Os autores do estudo, adaptando proposta de Senra e Lourenço (2016)

O método qualitativo (com análise do conteúdo dos textos) e quantitativo utilizado para buscar alcançar os objetivos do presente estudo consistiu de uma adaptação da revisão sistemática da literatura proposta por Senra e Lourenço (2016), conforme resumido na Figura 7.

O objetivo definido para este estudo (primeira fase) consistiu na proposição de um modelo teórico de pesquisa que consolidasse diferentes indicadores de como o alinhamento estratégico contribui para a eficácia da implementação de estratégias organizacionais, arranjado em categorias de recomendações da literatura. 
O longo intervalo temporal do estudo (segunda fase), definido como sendo as três últimas décadas contadas a partir do ano de 1990, se justificou pelo fato de que publicações de grande relevância da primeira década sobre o tema permanecem sendo utilizadas como referência para parte dos trabalhos recentes.

A base de dados eleita para a consulta (terceira fase) foi o Portal de Periódicos da Coordenação de Aperfeiçoamento de Pessoal de Nível Superior (CAPES), fundação vinculada ao Ministério da Educação (MEC) do Brasil, e a palavra-chave utilizada para as buscas foi strategic alignment e suas correspondentes expressões traduzidas para outras línguas da base (quando identificado automaticamente pela ferramenta de consulta do portal), necessariamente contidas nos títulos das publicações.

A quarta etapa consistiu no levantamento da bibliografia através das buscas de publicações contendo a palavra-chave e na catalogação dos textos obtidos na base de periódicos da CAPES.

A quinta etapa referiu-se à leitura flutuante das publicações, que consiste no contato inaugural com os documentos a analisar, para conhecer os textos e obter as primeiras impressões e orientações (BARDIN, 2000), seguido da definição dos critérios de inclusão e de exclusão de textos à pesquisa, conforme a relevância (SENRA; LOURENÇO, 2016). Neste estudo, a leitura flutuante foi efetuada nos títulos, palavraschave, tipos de publicação e resumos obtidos nas buscas na base de dados.

$\mathrm{Na}$ fase da leitura analítica (sexta), foi feita uma avaliação crítica dos textos para verificar a pertinência das publicações em relação à temática e aos objetivos da pesquisa.

A sétima etapa consistiu na catalogação dos textos válidos, com base nos indicadores descritivos, similarmente à fase de codificação sugerida por Bardin (2000), em que os dados coletados são organizados sistematicamente e agregados em unidades, permitindo a descrição das características do conteúdo.

A etapa da avaliação e síntese qualitativa para compreender o fenômeno (oitava fase) consistiu na análise qualitativa do material coletado para a identificação de aplicações práticas do alinhamento estratégico em estratégias organizacionais, e na sintetização de indicadores da eficácia da implementação de estratégias através do alinhamento.

A nona etapa consistiu na revisão sistemática com avaliação e síntese quantitativa para a integração dos resultados, efetuada com 0 auxílio de técnicas estatísticas que contribuem para aumentar a força das evidências científicas extraídas da fase anterior, processadas no programa IBM SPSS Statistics versão 22.

A última etapa (décima) foi desenhada para prestar contas do objetivo traçado para a pesquisa, à luz dos resultados e evidências científicas obtidos a partir das fases anteriores, informando se e como o objetivo proposto foi alcançado.

\section{Resultados}

O levantamento bruto da bibliografia, efetuado através da pesquisa pela chave strategic alignment nos títulos das publicações contidas na base de dados do Portal de Periódicos da CAPES, evidenciou os resultados iniciais da busca, através da exibição de 223 publicações de textos preliminarmente catalogados para que se relacionassem com os termos adotados para a realização da revisão sistemática, conforme recomendações de Senra e Lourenço (2016).

Após os descartes decorrentes dos critérios de exclusão e inclusão definidos na leitura flutuante, 25 publicações foram retiradas da base de análise por terem sido listadas mais de uma vez pelo Portal de Periódicos da CAPES, seja porque foram de fato publicadas mais de uma vez (caso em que foram descartados os textos a partir da segunda publicação), seja porque configuraram mera repetição da mesma publicação, na base. 


\section{Luís Alberto Monteiro de Barros e Antonio Max Martins dos Santos}

\begin{tabular}{lc}
\hline \multicolumn{1}{c}{ Periódico } & Frequência \\
\hline Reference \& Research Book News & 7 \\
Information \& Management & 6 \\
National Library of Australia & 5 \\
Information Systems Research & 4 \\
Information Resources Management Journal & 3 \\
International Journal of Operations \& Production Management & 3 \\
International Journal of Production Economics & 3 \\
Journal of Information Systems and Technology Management & 3 \\
Journal of Information Technology & 3 \\
Journal of Strategic Information Systems & 3 \\
MIS Quarterly & 3 \\
Revista Eletrônica de Sistemas de Informação & 3 \\
Outras publicações (em outros 130 periódicos) & 152 \\
\hline Total & 198 \\
\hline
\end{tabular}

Tabela 1 - Resumo das principais publicações consideradas válidas por periódico Fonte: Os autores deste estudo

Demais 198 obras consideradas válidas foram publicadas de forma desconcentrada em um grande número de periódicos, a maioria delas (152) distribuídas entre 130 periódicos acadêmicos que publicaram apenas 1 ou 2 vezes com o tema expresso no título, no intervalo temporal de busca. Outra evidência dessa desconcentração pôde ser observada através da análise descritiva dos 372 autores e coautores identificados nesses estudos, que revelou que 336 deles citaram apenas uma vez a expressão alinhamento estratégico nos títulos de seus trabalhos no período (Tabela 2), mesmo consideradas separadamente as autorias dos trabalhos conjuntos, sendo os mais produtivos os professores canadenses Louis Raymond e François Bergeron.

$\mathrm{Na}$ leitura analítica, para alcançar o objetivo da pesquisa de propor uma consolidação para o termo alinhamento estratégico em torno de aplicações práticas na implementação de estratégias organizacionais, a seleção das 53 obras que foram consideradas pertinentes utilizou como base de inclusão a presença, nos textos, dos principais aspectos a alinhar com a estratégia organizacional para que se obtenha a eficácia da sua implementação, recomendados na obra de Monteiro de Barros (2007), ou seja: recursos e capacidades; ações, controles; e desenho organizacional, havendo casos em que alguns desses 53 textos abordaram mais de um destes aspectos, totalizando 68 abordagens, conforme Tabela 3.

Para a descrição das características do conteúdo das obras inclusas na pesquisa, os indicadores (códigos) definidos para a catalogação dos textos foram: o tipo de publicação, o título, os autores, o nome da revista, 0 ano de publicação e o resumo (unidades de registro); bem como a área de conhecimento da publicação (unidade de contexto), que categorizou as obras ao longo da leitura analítica nas seguintes áreas: administração estratégica; estratégia e informação; gestão pública estratégica; estratégia nacional; educação; biologia; e biblioteconomia.

A Tabela 3 também apresenta a evidência de que as quatro primeiras áreas de conhecimento estão diretamente relacionadas com os temas organização e estratégia, sendo que um dos trabalhos na área da educação também trata indiretamente desses temas, uma vez que versa sobre desempenho mercadológico de escolas de negócios. Portanto, predomina na amostra trabalhos relacionados com as áreas de estratégia e negócios. 
ALINHAMENTO ORGANIZACIONAL PARA A IMPLEMENTAÇÃO DE ESTRATÉGIAS

\begin{tabular}{lllc}
\hline \multicolumn{1}{c}{ Autor } & Contagem & & Contagem \\
\hline Raymond, Louis & 6 & Hiekkanen, Kari & 2 \\
Bergeron, Francois & 4 & Hu, Clark & 2 \\
Abib, Gustavo & 3 & Huang, Leelien K. & 2 \\
Hoppen, Norberto & 3 & Kearns, Grover S. & 2 \\
Al-Ammary, Jaflah & 2 & Lederer, Albert L. & 2 \\
Andrews, Rhys & 2 & Lock, Russell & 2 \\
Avison, David & 2 & Luftman, Jerry & 2 \\
Bhansali, N & 2 & Mcadam, Rodney & 2 \\
Bleistein, Steven J. & 2 & Mockler, R. J. & 2 \\
Bruggeman, Werner & 2 & Pekkala, Anni & 2 \\
Cox, Karl & 2 & Powell, Philip & 2 \\
Dawson, Ray & 2 & Roth, Philip L. & 2 \\
Rezende, Jose Francisco de Carvalho & 2 & Rouse, David & 2 \\
Dutot, Vincent & 2 & Singh, Neha & 2 \\
Ellis - Braithwaite, Richard & 2 & Sledgianowski, Deb & 2 \\
Filho, Joaquim Rubens Fontes & 2 & Thatcher, Jason & 2 \\
Gerow, Jennifer E. & 2 & Verner, June & 2 \\
Grover, Varun & 2 & Outros 336 autores (com 1 publicação cada) & 336 \\
Haque, Badr & 2 & & 416 \\
\hline & & Total & 2 \\
\hline
\end{tabular}

Tabela 2 - Resumo das principais publicações consideradas válidas por periódico Fonte: Os autores deste estudo

A análise da evolução longitudinal do volume de publicações desde o início da década de 1990 demonstrou uma produção em picos cada vez maiores de obras sobre o tema ${ }^{2}$, com prevalência das áreas catalogadas como de administração estratégica e de estratégia e informação (gráfico 1). Mesmo considerando que todas as quatro áreas com mais publicações sobre o tema possuem alguma interseção de conteúdos com a gestão estratégica de organizações, principalmente com os negócios empresariais, destaca-se o interesse da área de TI pelo alinhamento estratégico e pelo desempenho organizacional.

\begin{tabular}{lcccccc}
\hline \multirow{2}{*}{ Área das publicações } & \multirow{2}{*}{$\begin{array}{c}\text { Total } \\
\text { válido }\end{array}$} & $\begin{array}{c}\text { Recursos e } \\
\text { capacidades }\end{array}$ & Ações & Controles & $\begin{array}{c}\text { Desenho } \\
\text { organizacional }\end{array}$ & $\begin{array}{c}\text { Total } \\
\text { pertinente }\end{array}$ \\
\hline Administração estratégica & 91 & 11 & 10 & 12 & 5 & 38 \\
Estratégia e informação & 91 & 13 & 9 & 1 & 2 & 25 \\
Gestão pública estratégica & 9 & 1 & 3 & 0 & 0 & 4 \\
Estratégia nacional & 3 & 0 & 0 & 0 & 0 & 0 \\
Educação & 2 & 0 & 1 & 0 & 0 & 1 \\
Biologia & 1 & 0 & 0 & 0 & 0 & 0 \\
Biblioteconomia & 1 & 0 & 0 & 13 & 7 & 0 \\
\hline Total & 198 & 25 & 23 & & 0 & 68 \\
\hline
\end{tabular}

Tabela 3 - Resumo das citações consideradas pertinentes por área de conhecimento após leitura analítica Fonte: Os autores deste estudo

A análise qualitativa do material coletado para a identificação de aplicações práticas do alinhamento estratégico em estratégias organizacionais permitiu compreender que os textos abordam esse fenômeno de 
diferentes pontos de vista. A síntese da análise qualitativa, por sua vez, sugere que há um eixo comum entre os variados textos e contextos, através do qual é possível encontrar indicadores do alinhamento estratégico, que favorecem a implementação da estratégia.

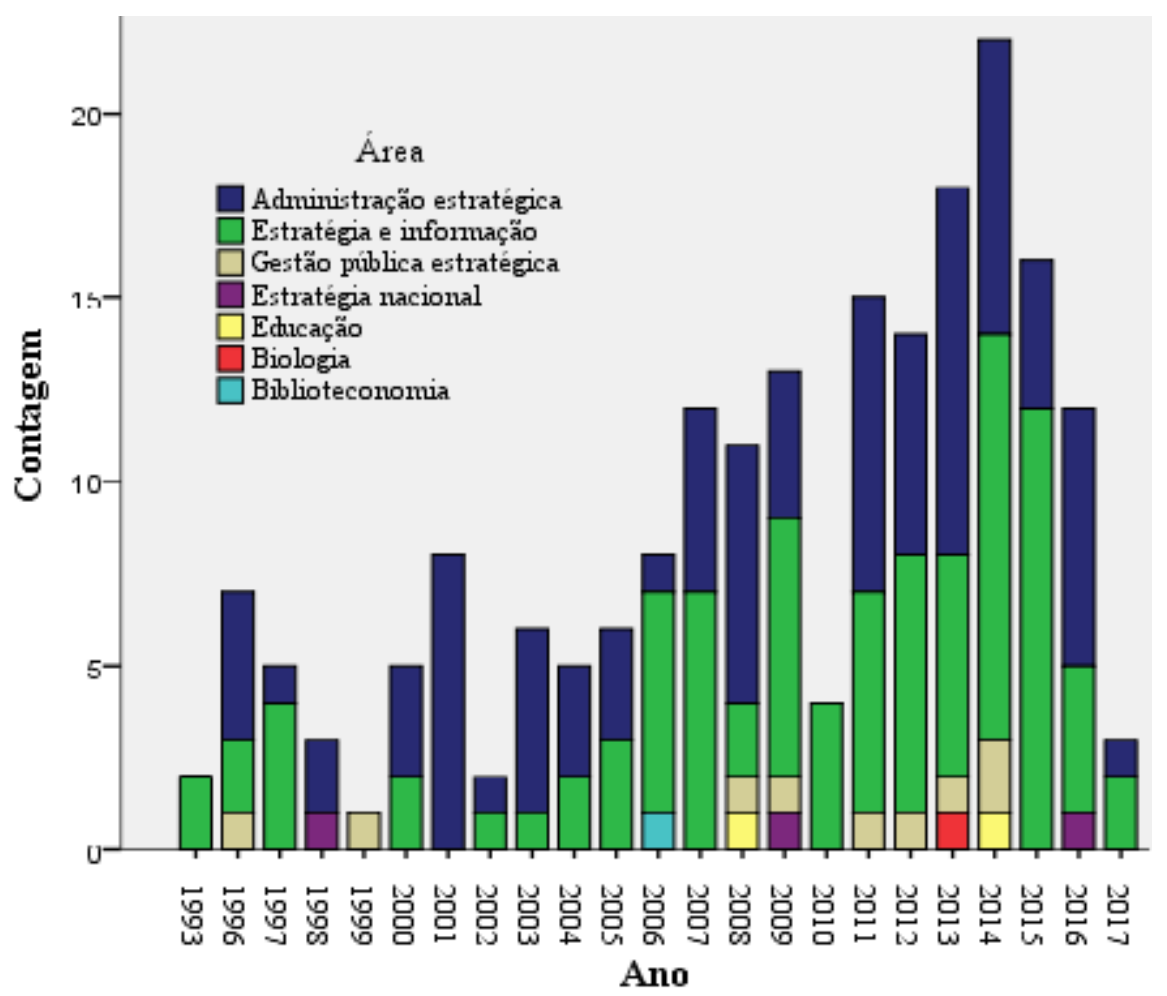

Gráfico 1 - Evolução histórica das publicações válidas por área de conhecimento Fonte: Os autores deste estudo

Através dessa síntese, tais indicadores, foram incorporados ao modelo de Monteiro de Barros (2007), segundo o qual a estratégia organizacional deve ser alinhada com os recursos e capacidades estratégicos da organização, com as ações direcionadas para implementar a estratégia, com os controles estratégicos e com o desenho organizacional, para que sua implementação seja eficaz.

Portanto, sintetizando as recomendações das publicações selecionadas para esta pesquisa, pode-se extrair primeiramente que, para alinhar a estratégia aos seus recursos e capacidades (quadro 4), as organizações devem desenvolver e implementar um plano de alocação dos recursos (CHIANG; NUNEZ, 2013) necessários para atingir as metas e objetivos estratégicos (EDWARDS, 2000), que geram (MADERO GÓMEZ; BARBOZA, 2015) ou estimulam a criação de valor, estando conectados com a estratégia de mercado (ZAKERY; AFRAZEH; DUMAY, 2017).

Devem também, para tanto, implementar um plano de desenvolvimento de capacidades de alinhamento (PETT; 2015), bem como de capacidades dinâmicas de resposta ao mercado (SARDANA; TERZIOVSKI; GUPTA, 2016), que forme lideranças considerando a estratégia da organização (CANALS; 2014), capacitando colaboradores estratégicos da organização para as competências e habilidades necessárias hoje e no futuro (MACARTHUR; BROST; DOUECK, 2004), com base nas funções a serem por eles desempenhadas e seus respectivos contextos (CANALS; 2014).

Todos os recursos e capacidades a serem desenvolvidos e alocados devem estar conectados à posição competitiva da organização, ajustando-os à sua estratégia e aos seus fatores externos e internos (RASHIDIRAD; SOLTANI; SYED, 2013), de tal forma que (por exemplo) as equipes técnicas precisam 
possuir, além das habilidades industriais e técnicas, profundo senso de negócios (PETT; 2015).

\begin{tabular}{|c|c|}
\hline Publicação & Recomendações para obter o alinhamento com a estratégia \\
\hline Canals (2014) & $\begin{array}{l}\text { a) As competências dos líderes se baseiam nas funções que ele deve } \\
\text { desempenhar e seus contextos específicos. } \\
\text { b) O desenvolvimento de lideranças considera a estratégia da organização e } \\
\text { seus objetivos. }\end{array}$ \\
\hline $\begin{array}{l}\text { Chao e Chandra } \\
\text { (2012) }\end{array}$ & $\begin{array}{l}\text { c) Tecnologia da informação focada em processos e áreas críticos para o } \\
\text { alcance dos objetivos estratégicos. }\end{array}$ \\
\hline $\begin{array}{l}\text { Chiang e Nunez } \\
\text { (2013) }\end{array}$ & a) Implementar plano de alocação de recursos. \\
\hline $\begin{array}{l}\text { Chou, Weng e Wu } \\
\text { (2013) }\end{array}$ & $\begin{array}{l}\text { a) Possuir capacidade de medir os principais indicadores para gerenciar } 0 \\
\text { desempenho. }\end{array}$ \\
\hline $\begin{array}{l}\text { Dutot, Bergeron e } \\
\text { Raymond (2014) }\end{array}$ & $\begin{array}{l}\text { a) A capacidade de processamento de informações da organização é } \\
\text { coerente com as suas necessidades. } \\
\text { b) A organização possui um sistema de comunicação que proporciona } \\
\text { informação precisa, completa, confiável e no tempo correto. }\end{array}$ \\
\hline Edwards (2000) & a) Adquirir os recursos necessários para atingir as metas e objetivos. \\
\hline $\begin{array}{l}\text { Macarthur, Brost e } \\
\text { Doueck (2004) }\end{array}$ & $\begin{array}{l}\text { a) Estruturar sistema integrado que contribua para a criação do plano } \\
\text { estratégico, para o comprometimento dos líderes com o alcance dos } \\
\text { objetivos e metas e para a melhoria contínua desse desempenho. } \\
\text { b) Treinar funcionários e gerentes para as competências e habilidades de } \\
\text { liderança necessárias para seus cargos atuais e futuros. }\end{array}$ \\
\hline $\begin{array}{l}\text { Madero Gómez e } \\
\text { Barboza (2015) }\end{array}$ & $\begin{array}{l}\text { a) Concentrar os recursos em atividades que realmente gerem valor aos } \\
\text { processos organizacionais. } \\
\text { b) Possuir sistemas de informação e comunicação eficientes. }\end{array}$ \\
\hline Pett (2015) & $\begin{array}{l}\text { a) Equipes estratégicas com pessoas de profundo senso de negócios, além } \\
\text { de habilidades industriais e técnicas. } \\
\text { b) Implementar plano estratégico para desenvolvimento das capacidades de } \\
\text { alinhamento. }\end{array}$ \\
\hline $\begin{array}{l}\text { Rashidirad, Soltani } \\
\text { e Syed (2013) }\end{array}$ & $\begin{array}{l}\text { a) Ajustar a estratégia da organização com seus fatores externos e internos, } \\
\text { ou seja, desenvolver recursos e capacidades alinhados à posição } \\
\text { competitiva da organização. }\end{array}$ \\
\hline $\begin{array}{l}\text { Sardana, Terziovski } \\
\text { e Gupta (2016) }\end{array}$ & $\begin{array}{l}\text { a) Desenvolver capacidades dinâmicas de resposta ao mercado, para } \\
\text { atender às demandas dos clientes. }\end{array}$ \\
\hline $\begin{array}{l}\text { Zakery, Afrazeh, e } \\
\text { Dumay (2017) }\end{array}$ & $\begin{array}{l}\text { a) Alinhar os recursos-chave da organização com a sua estratégia de } \\
\text { mercado. } \\
\text { b) Analisar problemas de gerenciamento de recursos para identificar os } \\
\text { componentes críticos que estimulem a criação de valor. }\end{array}$ \\
\hline
\end{tabular}

Quadro 4 - Recursos e capacidades

Fonte: Os autores deste estudo

Os recursos e capacidades relacionados à TI cumprem um papel importante nessa dimensão do alinhamento estratégico, tendo em vista a sua importância para a eficácia da implementação da estratégia. Dessa forma, a organização precisa estruturar um sistema de informação integrado que não se limite ao desenvolvimento do plano estratégico, mas também promova o desempenho da organização, através do comprometimento dos líderes e da melhoria contínua (MACARTHUR; BROST; DOUECK, 2004), que produzam informações precisas, completas, confiáveis e no tempo correto (DUTOT; BERGERON; 
RAYMOND, 2014).

A tecnologia da informação, portanto, deve estar focada em processos e áreas estratégicos (CHAO; CHANDRA, 2012), na forma de sistemas de informação e comunicação eficientes (MADERO GÓMEZ; BARBOZA, 2015) e com capacidade de processar informações coerente com as necessidades da organização (DUTOT; BERGERON; RAYMOND, 2014).

Por segundo, em relação às ações direcionadas para implementar a estratégia (quadro 5), depreende-se da base teórica consultada que o resultado obtido a partir dos colaboradores começa a ser viabilizado no topo da estrutura organizacional. Ou seja, a alta administração deve apoiar os envolvidos nas iniciativas estratégicas (PETT, 2015) e estar comprometida com o sucesso das ações das lideranças (CANALS, 2014). O principal executivo da organização precisa envolver-se com a implementação da estratégia, reconhecendo e conduzindo comportamentos apropriados nesse sentido (EDWARDS; 2000).

\begin{tabular}{|c|c|}
\hline Publicação & Recomendações para obter o alinhamento com a estratégia \\
\hline Alcoba $(2014)$ & $\begin{array}{l}\text { a) Obter o comprometimento e o esforço dos responsáveis em relação: } \\
\text { - à compreensão e adoção dos planos; e } \\
\text { - à implementação do projeto planejado. }\end{array}$ \\
\hline $\begin{array}{l}\text { Almeida e } \\
\text { Santos (2015) }\end{array}$ & a) Desdobrar as decisões estratégicas em ações, para coloca-las em prática. \\
\hline $\begin{array}{l}\text { Biggs, Brough e } \\
\text { Barbour (2014) }\end{array}$ & $\begin{array}{l}\text { a) Utilização de recursos de interface entre o indivíduo e a organização. } \\
\text { b) Colaboradores ajustam as tarefas na empresa com as prioridades } \\
\text { estratégicas da organização. } \\
\text { c) Colaboradores têm uma compreensão clara acerca de como as suas } \\
\text { tarefas se encaixam nos objetivos gerais da organização. } \\
\text { d) Dar feedback e reforçar o comportamento apropriado dos colaboradores. } \\
\text { e) Colaboradores investem energia pessoal para o desempenho de suas } \\
\text { tarefas. }\end{array}$ \\
\hline Canals (2014) & $\begin{array}{l}\text { a) A alta administração está comprometida com o sucesso das ações das } \\
\text { lideranças. }\end{array}$ \\
\hline $\begin{array}{l}\text { Dulipovici e Robey } \\
\text { (2013) }\end{array}$ & $\begin{array}{l}\text { a) Usuários efetivamente interagem com os novos sistemas estratégicos, no } \\
\text { dia-a-dia dos seus trabalhos. }\end{array}$ \\
\hline Edwards (2000) & $\begin{array}{l}\text { a) Principal executivo está envolvido na implementação da estratégia. } \\
\text { b) Principal executivo reconhece e conduz comportamentos apropriados à } \\
\text { implementação da estratégia. } \\
\text { c) Recompensar as pessoas pela obtenção de resultados. }\end{array}$ \\
\hline Halter (2015) & $\begin{array}{l}\text { a) Alinhar grupos de trabalho, departamentos, divisões e partes interessadas } \\
\text { com as metas e objetivos da organização. }\end{array}$ \\
\hline Isal e outros (2016) & $\begin{array}{l}\text { a) Distribuir as informações estratégicas apropriadas às partes internas e } \\
\text { externas da organização }\end{array}$ \\
\hline $\begin{array}{l}\text { Madero Gómez e } \\
\text { Barboza (2015) }\end{array}$ & $\begin{array}{l}\text { a) A cultura organizacional facilita as mudanças através de soluções mais } \\
\text { flexíveis. } \\
\text { b) A organização comunica claramente aos colaboradores quais são as } \\
\text { ações estratégicas a serem executadas para eles alcançarem os objetivos. }\end{array}$ \\
\hline Pett (2015) & $\begin{array}{l}\text { a) Obtenção de um forte envolvimento da equipe; } \\
\text { b) Harmonizar funções gerenciais para garantir um foco comum em relação à } \\
\text { direção estratégica da empresa. } \\
\text { c) Fornecer apoio da alta administração aos envolvidos nas iniciativas } \\
\text { estratégicas. }\end{array}$ \\
\hline
\end{tabular}

Quadro 5 - Ações

Fonte: Os autores deste estudo 
É necessária uma cultura organizacional que facilite as mudanças impostas pela estratégia (MADERO GÓMEZ; BARBOZA, 2015), em que os usuários efetivamente interajam com os novos sistemas estratégicos, no dia-a-dia dos seus trabalhos (DULIPOVICI; ROBEY, 2013), as áreas funcionais operem sempre com foco comum, em relação à direção estratégica (PETT, 2015), e a organização mantenha uma distribuição das informações estratégicas apropriadas às partes internas e externas da organização (ISAL et al, 2016).

Com o objetivo de se obter efetividade das ações estratégicas, é preciso desdobrar as estratégias em ações (ALMEIDA; SANTOS, 2015), comunicar claramente aos colaboradores quais são essas iniciativas a serem executadas para eles alcançarem os objetivos (MADERO GÓMEZ; BARBOZA, 2015), de forma que eles compreendam como essas suas tarefas se encaixam nos objetivos gerais da organização e eventualmente as ajustam de acordo com as prioridades estratégicas da entidade (BIGGS; BROUGH; BARBOUR, 2014).

\begin{tabular}{|c|c|}
\hline Publicação & Recomendações para obter o alinhamento com a estratégia \\
\hline $\begin{array}{l}\text { Cäker e Siverbo } \\
(2014)\end{array}$ & $\begin{array}{l}\text { a) Utilizar conjuntamente controles sócio-ideológicos e controles } \\
\text { tecnocráticos. } \\
\text { b) Monitorar o desempenho. }\end{array}$ \\
\hline $\begin{array}{l}\text { Chiang e Nunez } \\
\text { (2013) }\end{array}$ & a) Controlar os prazos de execução. \\
\hline $\begin{array}{l}\text { Chou, Weng e Wu } \\
\text { (2013) }\end{array}$ & a) Medir os principais indicadores para gerenciar o desempenho. \\
\hline $\begin{array}{l}\text { Damke, Silva e } \\
\text { Walter (2011) }\end{array}$ & $\begin{array}{l}\text { a) Utilizar sistema de monitoramento de resultados. } \\
\text { b) Elaborar objetivos e metas claros. } \\
\text { c) Monitorar metas e objetivos efetiva e periodicamente. } \\
\text { d) Gestores avaliam se o que foi planejado foi alcançado. } \\
\text { e) Avaliar individualmente os responsáveis pelas metas da organização. } \\
\text { f) Permitir exceções, em caso de não cumprimento pleno da meta. } \\
\text { g) Negociar metas com base em relatórios e controles internos. }\end{array}$ \\
\hline Edwards (2000) & a) Articular visão clara, metas e objetivos alcançáveis para atingir essa visão. \\
\hline $\begin{array}{l}\text { Lawrie e outros } \\
\text { (2016) }\end{array}$ & $\begin{array}{l}\text { a) Utilizar sistema de controle estratégico baseado em balanced scorecards. } \\
\text { b) Rastrear o impacto das atividades de implementação da estratégia sobre a } \\
\text { organização. }\end{array}$ \\
\hline $\begin{array}{l}\text { Macarthur, Brost e } \\
\text { Doueck (2004) }\end{array}$ & $\begin{array}{l}\text { a) Utilizar modelos de mensuração do desempenho para monitorar o } \\
\text { progresso em direção às metas e objetivos. } \\
\text { b) Monitorar e avaliar o desempenho dos gerentes e demais colaboradores. }\end{array}$ \\
\hline Pett (2015) & $\begin{array}{l}\text { a) Monitorar os riscos potenciais relacionados a iniciativas críticas da } \\
\text { empresa antes das ocorrências dos riscos. } \\
\text { b) Estabelecer métricas para definir o sucesso das iniciativas estratégicas. } \\
\text { c) Monitorar periodicamente as métricas estratégicas. } \\
\text { d) Avaliar e revisar os planos estratégicos à medida que eles são } \\
\text { implementados. }\end{array}$ \\
\hline $\begin{array}{l}\text { Villa González del } \\
\text { Pino, Pons Murguía } \\
\text { e Bermudez Villa } \\
\text { (2014) }\end{array}$ & $\begin{array}{l}\text { a) Desenhar um sistema de controle de gestão para o alinhamento } \\
\text { estratégico. } \\
\text { b) Monitorar periodicamente o comportamento dos indicadores de } \\
\text { desempenho. }\end{array}$ \\
\hline $\begin{array}{l}\text { Zakery, Afrazeh, e } \\
\text { Dumay (2017) }\end{array}$ & a) Medir e monitorar os efeitos das iniciativas empreendidas. \\
\hline
\end{tabular}

Quadro 6 - Controles

Fonte: Os autores deste estudo 


\section{Luís Alberto Monteiro de Barros e Antonio Max Martins dos Santos}

Para obter um forte envolvimento da equipe em torno do projeto (PETT, 2015) e um comprometimento e esforço dos responsáveis (ALCOBA, 2014), além de alinhar grupos de trabalho, departamentos, divisões e partes interessadas com os objetivos e as metas pretendidos (HALTER, 2015), é imprescindível desenvolver uma interface entre os indivíduos e a organização para que os colaboradores invistam energia pessoal nas tarefas. Constatado o alcance dos objetivos e metas, deve-se fornecer feedback e reforçar o comportamento apropriado dos colaboradores (BIGGS; BROUGH; BARBOUR, 2014), bem como recompensar as pessoas pela obtenção dos resultados (EDWARDS, 2000).

Terceiro, a síntese da base teórica indica que o controle da estratégia (quadro 6) deve partir do desenho de um sistema de controle para avaliar a estratégia (LAWRIE et al, 2016) e para a gestão do alinhamento estratégico (VILLA GONZÁLEZ DEL PINO; PONS MURGUÍA; BERMUDEZ VILLA. 2014). Esse sistema pressupõe a articulação de uma visão clara (EDWARDS, 2000), bem como objetivos e metas alcançáveis para atingir essa visão (EDWARDS, 2000, DAMKE; SILVA; WALTER, 2011), negociadas com base em relatórios e controles internos (DAMKE; SILVA; WALTER, 2011).

Tal sistema pode incluir conjuntamente controles sócio ideológicos (normativos, controle de pessoas, grupos e aspirações e sistemas de crenças) e controles tecnocráticos (projetados para permitir 0 autogerenciamento) ${ }^{3}$, uma vez que eles são complementares no monitoramento do alinhamento estratégico (CÄKER; SIVERBO, 2014).

Após estabelecer métricas do sucesso das iniciativas estratégicas (PETT, 2015), os gestores avaliam se 0 que foi planejado foi alcançado, bem como avaliam individualmente os responsáveis pelas metas da organização (DAMKE; SILVA; WALTER, 2011), controlando os prazos de execução (CHIANG; NUNEZ, 2013) e revisando eventualmente os planos estratégicos à medida que eles são implementados (PETT, 2015).

Para tanto, a instituição deve utilizar sistema de monitoramento permanente do progresso dos resultados (DAMKE; SILVA; WALTER, 2011), do desempenho da organização (CÄKER; SIVERBO, 2014) através dos seus indicadores (VILLA GONZÁLEZ DEL PINO; PONS MURGUÍA; BERMUDEZ VILLA, 2014; CHOU; WENG; WU, 2013), dos gerentes e demais colaboradores, dos objetivos e metas (DAMKE; SILVA; WALTER, 2011; MACARTHUR; BROST; DOUECK, 2004), e demais métricas estratégicas (PETT, 2015).

Deve ainda a organização medir e monitorar os efeitos das iniciativas empreendidas (ZAKERY; AFRAZEH; DUMAY, 2017), rastreando o impacto da sua implementação internamente (LAWRIE et al. 2016), inclusive com relação aos riscos das iniciativas estratégicas (PETT, 2015), e permitindo exceções, em caso de não cumprimento pleno de alguma meta (DAMKE; SILVA; WALTER, 2011).

Quarto e último, ajustar o desenho organizacional à estratégia passa por implementar um modelo de gestão que esteja de acordo com o direcionamento estratégico da organização (VILLA GONZÁLEZ DEL PINO; PONS MURGUÍA; BERMUDEZ VILLA, 2014), formatando a organização para maximizar o alinhamento entre a alta administração e a gerência intermediária, para proporcionar o nível de coordenação e controle desejados (ANDREWS; BEYNON, 2011), o nível de descentralização desejado (SILVESTRO, R.; SILVESTRO, C., 2003), viabilizando a inter-relação conjunta entre controles sócio ideológicos e tecnocráticos (CÄKER; SIVERBO, 2014).

A estrutura organizacional alinhada à estratégia, nesse sentido, oferece apoio para todos os colaboradores (MADERO GÓMEZ; BARBOZA, 2015), facilita a movimentação da informação através das áreas funcionais, apresenta mecanismos internos de colaboração e de aprendizado interativo, está orientada para o gerenciamento de desempenho e eficiência (CHOU; WENG; WU, 2013), para melhorar o conjunto completo de atividades dentro de processos e subprocessos, inclusive os processos para atender aos requisitos dos clientes (MACARTHUR; BROST; DOUECK, 2004), sendo possível reconfigurar nela os processos internos necessários para executar uma eventual nova estratégia (CHOU; WENG; WU, 2013). 


\begin{tabular}{|c|c|}
\hline Publicação & Recomendações para obter o alinhamento com a estratégia \\
\hline $\begin{array}{l}\text { Andrews e Beynon } \\
\text { (2011) }\end{array}$ & $\begin{array}{l}\text { a) Formatar a organização de maneira a maximizar o alinhamento entre a } \\
\text { alta administração e a gerência intermediária. } \\
\text { b) Formatar a organização de forma a proporcionar o nível de coordenação e } \\
\text { controle desejados. }\end{array}$ \\
\hline $\begin{array}{l}\text { Cäker e Siverbo } \\
(2014)\end{array}$ & $\begin{array}{l}\text { a) Formatar a organização de forma viabilizar a inter-relação entre controles } \\
\text { sócio-ideológicos e tecnocráticos. }\end{array}$ \\
\hline $\begin{array}{l}\text { Chou, Weng e Wu } \\
\text { (2013) }\end{array}$ & $\begin{array}{l}\text { a) Estruturar a organização de modo a facilitar que a informação se } \\
\text { movimente facilmente através de diferentes áreas funcionais. } \\
\text { b) Reconfigurar processos internos para executar a nova estratégia. } \\
\text { c) Projetar a estrutura para o gerenciamento de desempenho e eficiência. } \\
\text { d) Estruturar mecanismos internos de colaboração e de aprendizado } \\
\text { interativo. }\end{array}$ \\
\hline $\begin{array}{l}\text { Macarthur, Brost e } \\
\text { Doueck (2004) }\end{array}$ & $\begin{array}{l}\text { a) Implementar estrutura organizacional baseada em processos, que se } \\
\text { concentre em melhorar o conjunto completo de atividades dentro de } \\
\text { processos e subprocessos. } \\
\text { b) Desenhar os processos para atender aos requisitos dos clientes. }\end{array}$ \\
\hline $\begin{array}{l}\text { Madero Gómez e } \\
\text { Barboza (2015) }\end{array}$ & a) Desenhar uma estrutura de apoio para todos os colaboradores. \\
\hline $\begin{array}{l}\text { Silvestro, } \mathrm{R} \mathrm{e} \\
\text { Silvestro, C (2003) }\end{array}$ & $\begin{array}{l}\text { a) Formatar a organização de forma a proporcionar o nível de } \\
\text { descentralização desejado. }\end{array}$ \\
\hline $\begin{array}{l}\text { Villa González del } \\
\text { Pino, Pons Murguía } \\
\text { e Bermudez Villa } \\
\text { (2014) }\end{array}$ & $\begin{array}{l}\text { a) Implementar modelo de gestão de acordo com o direcionamento } \\
\text { estratégico da organização. }\end{array}$ \\
\hline
\end{tabular}

Quadro 7 - Desenho organizacional

Fonte: Os autores deste estudo

A análise quantitativa efetuada neste estudo contribuiu não apenas para dimensionar a produção acadêmica em torno do tema alinhamento estratégico, mas auxiliou também na organização e distribuição dos textos em categorias, para que se compreendesse melhor as características dos textos que se pretendia investigar, especialmente aquelas relacionadas à implementação de estratégias.

A síntese da análise quantitativa permitiu demonstrar estatisticamente que o material bibliográfico coletado provém de diversas áreas do conhecimento e pode ser distribuído entre as combinações de sistemas que compõem o modelo de Monteiro de Barros (2007) para a obtenção de eficácia da implementação da estratégia (Tabela 3), fornecendo suporte ao framework teórico.

Integrando esses resultados àqueles obtidos a partir da avaliação e síntese qualitativa, tem-se que a incorporação dos indicadores do alinhamento estratégico (que favorecem a implementação da estratégia) identificados nos textos categorizados na tabela 3 permitem a elaboração de uma proposta de modelo de alinhamento que consolide teoricamente o termo alinhamento estratégico em torno do eixo específico de aplicações práticas na implementação de estratégias organizacionais (Figura 8).

No modelo proposto, os códigos RC1, RC2, RC3 e RC4 denotam indicadores do alinhamento entre os recursos e capacidades e a estratégia; $\mathrm{CO} 1, \mathrm{CO} 2, \mathrm{CO} 3$ e $\mathrm{CO} 4$ são indicadores do alinhamento entre os controles e a estratégia; IN1, IN2, IN3, IN4 e IN5 são indicadores do alinhamento entre a estratégia e as ações (iniciativas) para implementá-la; e OD1, OD2, OD3 e OD4 são indicadores do alinhamento entre 0 desenho organizacional e a estratégia. 


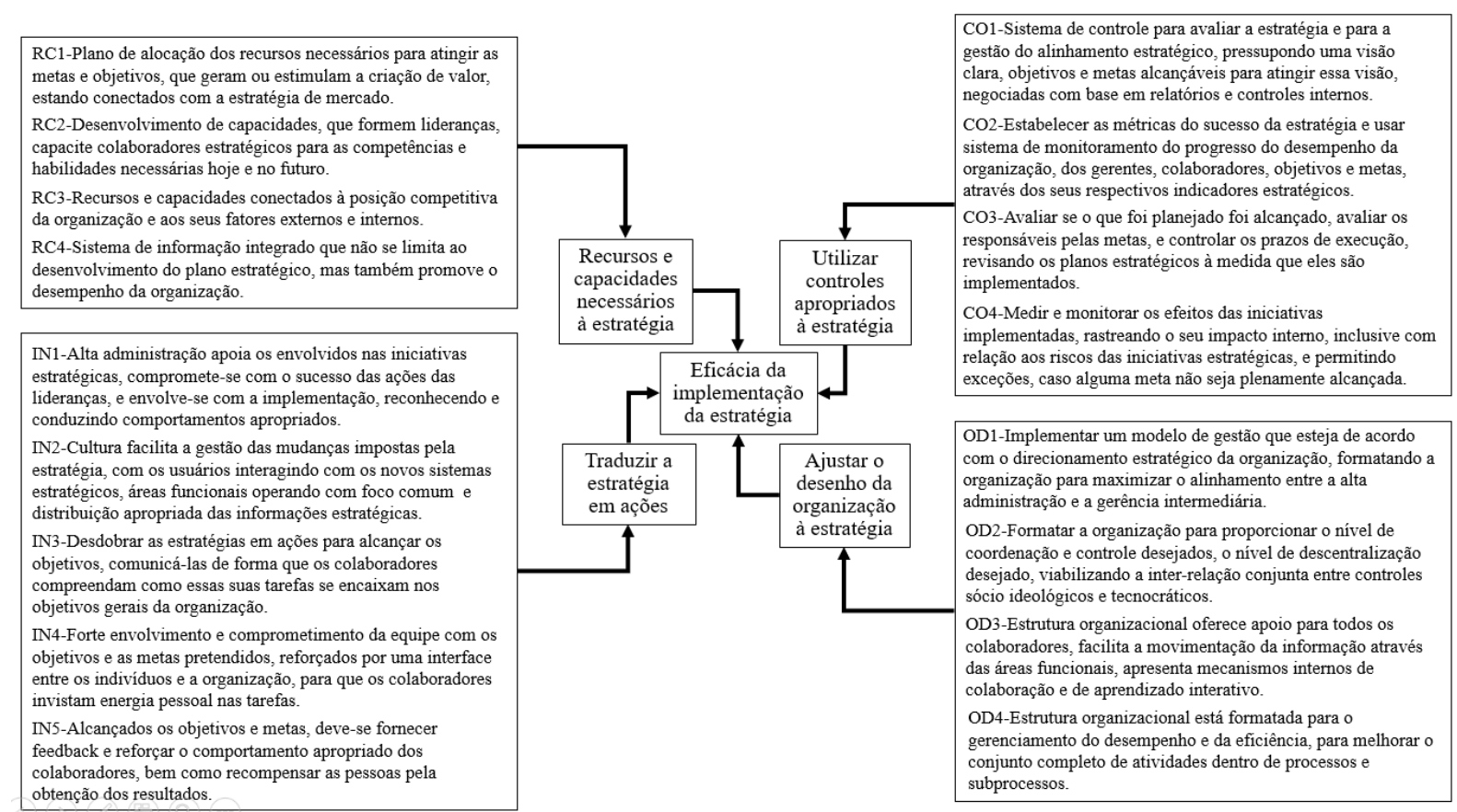

Figura 8 - Proposta de modelo de alinhamento para a implementação de estratégia Fonte: Os autores deste estudo

Ou seja, segundo esta proposição teórica, a eficácia da implementação da estratégia organizacional depende dos alinhamentos da estratégia com os seguintes aspectos necessários para implementá-la: os recursos e capacidades; as ações; os controles; e o desenho da organização. Para operacionalizar esses alinhamentos, portanto, o modelo propõe que as organizações devem colocar em prática cada uma das recomendações sugeridas pelos diversos indicadores nele destacados, para obter e sustentar os recursos e capacidades necessários à implementação da estratégia da organização, traduzir as suas estratégias em ações, aplicar os controles necessários à implementação da estratégia, e ajustando a esta o desenho da organização.

A gestão conjunta desses indicadores proporciona, conforme o modelo teórico proposto, o alinhamento necessário para que se implemente eficazmente a estratégia organizacional, e a base acadêmica que sustenta a aplicabilidade desses indicadores foi consolidada nos quadros 4, 5, 6 e 7, nos quais se pode encontrar informações adicionais sobre cada um desses indicadores.

\section{Considerações finais}

O conceito de alinhamento estratégico teve a sua origem na gestão da estratégia organizacional. Influenciado pelo grande potencial integrador das crescentes tecnologias da informação às organizações, passou o termo a ser associado por acadêmicos relacionados de alguma forma à área de $\mathrm{TI}$ como um meio, através do qual seria possível ampliar o desempenho organizacional.

Progressivamente, entretanto, estudiosos da estratégia organizacional passaram a adotar o termo para fazer referência a abordagens gerenciais mais abrangentes na perseguição de níveis mais elevados de desempenho, sendo estes enfoques não necessariamente excludentes, em relação às abordagens informacionais.

Há diversas abordagens acerca do tema alinhamento estratégico, tanto no campo da administração como na da tecnologia da informação e em outras áreas do conhecimento. Mesmo abordagens classificadas em uma mesma área do conhecimento possuem divergências entre si, como aquelas entre o modelo de Henderson e Venkatraman (1993) e o modelo de Dutot, Bergeron e Raymond (2014), ambos baseados na 
área da TI. Entretanto, as diversas abordagens classificadas como sendo relativas às áreas da tecnologia da informação e da administração (e mesmo aquelas de outras áreas do conhecimento) nunca se apresentam excludentes entre si, apresentando divergências, mas também convergências conceituais, não se está tratando necessariamente de fenômenos absolutamente diferentes.

As convergências entre essas diversas abordagens classificadas como sendo relativas às áreas da tecnologia da informação e da administração confirmam que a gestão da informação constitui importante recurso estratégico organizacional. Mais que isso. Todas as abordagens classificadas como sendo relativas às áreas da tecnologia da informação e da administração sugerem que o alinhamento consiste em um meio através do qual se poderia alcançar o objetivo estratégico, ou seja, alcançar a eficácia da estratégia.

No que se refere ao alinhamento que produz a eficácia da implementação da estratégia organizacional, há, em tese, várias formas de se alcançá-lo, encontrando-se a singularidade do modelo teórico proposto neste estudo na constatação de que se trata de inédita consolidação de vasta produção acadêmica sobre o tema, colecionada ao longo das últimas décadas, após os filtros e análises quantitativa e qualitativa efetuados especificamente com esse propósito.

Segundo essa proposta (Figura 8), há uma relação direta dos indicadores de cada uma das respectivas dimensões do modelo proposto (recursos e capacidades necessários à estratégia; tradução da estratégia em ações; controles apropriados à estratégia; e ajuste do desenho organizacional à estratégia) com a eficácia da implementação da estratégia, indicando uma forma como o alinhamento contribui para a eficácia da implementação de estratégias organizacionais e arranjando as recomendações da base teórica em categorias de aspectos a alinhar para que se obtenha a eficácia da implementação de estratégias organizacionais, restando, portanto, respondidas as duas questões de pesquisa lançadas. Em resumo, promove-se eficácia da implementação de estratégias organizacionais alinhando a estratégia:

a) aos recursos e capacidades necessários para a sua implementação:

- implementando plano de alocação dos recursos necessários para atingir as metas e objetivos, que geram ou estimulam a criação de valor, estando conectados com a estratégia de mercado;

- desenvolvendo capacidades, que formem lideranças e capacite colaboradores estratégicos para as competências e habilidades necessárias hoje e no futuro;

- conectando esses recursos e capacidades à posição competitiva da organização e aos seus fatores externos e internos; e

- utilizando sistema de informação integrado que contribua para o desenvolvimento do plano estratégico e para a promoção do desempenho da organização.

b) às ações a serem implementadas:

- com a alta administração apoiando os envolvidos nas iniciativas estratégicas, comprometendo-se com o sucesso das ações das lideranças, e envolvendo-se com a implementação, reconhecendo e conduzindo os comportamentos apropriados;

- estimulando uma cultura que facilita a gestão das mudanças impostas pela estratégia, com os usuários interagindo com os novos sistemas estratégicos, as áreas funcionais operando com foco comum e com a distribuição apropriada das informações estratégicas;

- desdobrando as estratégias em ações para alcançar os objetivos, comunicando-as de forma que os colaboradores compreendam como as suas tarefas se encaixam nos objetivos gerais da organização;

- promovendo forte envolvimento e comprometimento da equipe com os objetivos e as metas pretendidos, reforçados por uma interface entre os indivíduos e a organização, para que os colaboradores invistam energia pessoal nas tarefas; $\mathrm{e}$

- alcançados os objetivos e metas, fornecendo feedback e reforçando o comportamento apropriado dos colaboradores, bem como recompensando as pessoas pela obtenção dos resultados.

c) aos controles necessários para a sua implementação: 
- implementando sistema de controle para avaliar a estratégia e para a gestão do alinhamento estratégico, pressupondo uma visão clara, objetivos e metas alcançáveis para atingir essa visão, negociadas com base em relatórios e controles internos;

- estabelecendo as métricas do sucesso da estratégia e utilizando sistema de monitoramento do progresso do desempenho da organização, dos gerentes, colaboradores, objetivos e metas, através dos seus respectivos indicadores estratégicos;

- avaliando se o que foi planejado foi alcançado, avaliando os responsáveis pelas metas, controlando os prazos de execução, bem como revisando os planos estratégicos à medida que eles são implementados; e

- medindo e monitorando os efeitos das iniciativas implementadas, rastreando o seu impacto interno, inclusive com relação aos riscos das iniciativas estratégicas, e permitindo exceções, caso alguma meta não seja plenamente alcançada.

d) ao desenho organizacional:

- implementando um modelo de gestão que esteja de acordo com o direcionamento estratégico da organização, bem como formatando a organização para maximizar o alinhamento entre a alta administração e a gerência intermediária;

- formatando a organização para proporcionar o nível de coordenação, controle e descentralização desejados, viabilizando a inter-relação conjunta entre controles sócio ideológicos e tecnocráticos;

- fazendo com que a estrutura organizacional ofereça apoio para todos os colaboradores, facilite a movimentação da informação através das áreas funcionais, bem como apresente mecanismos internos de colaboração e de aprendizado interativo; e

- formate a estrutura organizacional para o gerenciamento do desempenho e da eficiência, para melhorar o conjunto completo de atividades dentro de processos e subprocessos.

Retomando o objetivo da pesquisa, que foi declarado ao início como sendo de propor um modelo teórico que consolidasse diferentes indicadores de como 0 alinhamento estratégico contribuiria para a eficácia da implementação de estratégias organizacionais, a fim de testar futuramente o modelo no campo, considerase que o mesmo foi alcançado, uma vez que a proposta de modelo resultante das análise efetuadas neste estudo (Figura 8), obtida através da metodologia de pesquisa empregada, apresenta arranjo lógico de categorias de indicadores de alinhamento que conduzem à eficácia da implementação de estratégias, podendo os vínculos teóricos entre esses indicadores e a eficácia da implementação da estratégia serem considerados hipóteses a serem testadas em estudos futuros, contribuindo para o conhecimento e a aplicação prática de um fator crucial para as organizações, que é o alcance de um desempenho dentro do esperado, em relação aos seus objetivos.

\section{Notas}

1 Os dados da pesquisa de 2017 referem-se ao período de janeiro a junho (mês da coleta dos dados), de forma que desconsideram, a produção acadêmica postada na base de periódicos da CAPES nos meses seguintes daquele ano.

2 Em resumo, Miles e outros (1978) afirmam que a organização defensora mantém um ambiente para o qual uma forma estável de organização é apropriada, enquanto a prospectora cria um ambiente mais dinâmico, no mesmo setor. A organização analisadora, segundo eles, consiste em uma combinação única da prospectora com a defensora.

3 Conforme Cäker e Siverbo, os controles tecnocráticos visam a especificação do que deve ser feito ou do que deve ser alcançado, normalmente através se regras, procedimentos, normas, orçamentos, medidas de desempenho e sistemas de recompensa (2014), e os controles sócio ideológicos constroem e mantêm a confiança na experiência baseada em aconselhamento e proximidade entre indivíduos na organização, principalmente sob a forma de práticas de gestão de pessoas (2014). 


\section{Referências}

ABIB, Gustavo; HOPPEN, Norberto. O papel do consultor no processo de alinhamento estratégico. Revista de Administração Contemporânea, Rio de Janeiro, v. 19, n. 5, p. 584-605, set./out. 2015.

AHMADI, S. A. A.; SALAMZADEH, Y.; DARAEI, M.; AKBARI, J. Relationship between organizational culture and strategy implementation: typologies and dimensions. Global Business and Management Research: An International Journal, v. 4 n. 3-4, p. 286-299, Jul.-Oct. 2012.

ALCOBA, Jesus. Strategic alignment in business education: the second magic bullet. Journal of Education for Business, London, v. 89, n. 3, p. 119-125, 2014.

ALMEIDA, Laércio M.; SANTOS, Ernani M. Análise da promoção das práticas do alinhamento estratégico entre negócio e tecnologia da informação: um estudo de caso em organização de serviços. Revista Gestão.Org, Recife, v. 13, Edição Especial, p 187-199, 2015.

ANDREWS, Rhys; BEYNON, Malcolm J. Organizational form and strategic alignment in a local authority: a preliminary exploration using fuzzy clustering. Public Organization Review, Cham, v.11, n. 3, p. 201-218, 2011.

ANSOFF, Igor H.; DECLERCK, Roger P.; HAYES, Robert L. (eds.). From strategic planning to strategic management. London: Wiley, 1976.

BARDIN, Laurence. Análise de conteúdo. Lisboa: Edições 70, 2000.

BERGERON, François; RAYMOND, Louis. Enabling the business strategy of SMEs through e-business capabilities: a strategic alignment perspective. Industrial Management \& Data Systems, Bingley, v. 108, n. 5, p. 577-595, 2008.

BERGERON, François; RAYMOND, Louis; RIVARD, Suzanne. Ideal patterns of strategic alignment and business performance. Information \& Management, Amsterdam, v. 41, n. 8, p. 1003-1020, 2004.

BROWN, Susan. Strategic alignment for 21st century literacies. Literacy Learning: The Middle Years, Adelaide, v. 16, n. 3, p. 38-40, Oct. 2008.

BIGGS, Amanda; BROUGH, Paula; BARBOUR, Jennifer P. Strategic alignment with organizational priorities and work engagement: a multi-wave analysis. Journal of Organizational Behavior, Hoboken, v. 35, n. 3, p. 301-317, 2014.

CÄKER, Mikael; SIVERBO, Sven. Strategic alignment in decentralized organizations: the case of Svenska Handelsbanken. Scandinavian Journal of Management, Amsterdam, v. 30, n. 2, p. 149-162, June 2014.

CAMERON, K. S. Effectiveness as paradox: consensus and conflict in conceptions of organizational effectiveness. In: Management Science. Linthicum, v. 32, n. 5, p. 539-553, May 1986.

CANALS, Jordi. Global leadership development, strategic alignment and CEOs commitment. Journal of Management Development, Bingley, v. 33, n. 5, p. 487-502, 2014.

CHAN, Yolande E.; HUFF, Sid L.; BARCLAY, Donald W.; COPELAND, Duncan G. Business strategic orientation, information system orientation, and strategic alignment. Information Systems Research, Catonsville, v. 8, n. 2, p. 125-150, 1997.

CHAN, Yolande E.; SABHERWAL, Rajiv; THATCHER, Jason Bennett. Antecedents and outcomes of strategic IS alignment: an empirical investigation. IEEE Transactions on Engineering Management, Piscataway, v. 53, n. 1, p. 27-47, 2006.

CHAO, Chia-An; CHANDRA, Aruna. Impact of owner's knowledge of information technology (IT) on strategic alignment and IT adoption in US small firms. Journal of Small Business and Enterprise Development, Bingley, v. 19, n. 1, p. 114-131, 2012. 
CHIANG, I. Robert; NUNEZ, Manuel A. Strategic alignment and value maximization for IT project portfolios. Information Technology and Management, Cham, v. 14, n. 2, p. 143-157, June 2013.

CHOU, Tzu-Chuan; WENG, Pu-Dong; WU, Tzong-Chen. Exploring design-fits for the strategic alignment of information systems with business objectives, Information Research-An International Electronic Journal, Borås, v. 18, n. 1, Mar. 2013. Não paginado.

COOPER, Cary L.; ARGYRIS, Chris (Orgs). Dicionário enciclopédico de administração. São Paulo: Atlas, 2003.

DAMKE, Elói Júnior; SILVA, Eduardo D.; WALTER, Silvana A. Sistemas de controle e alinhamento estratégico: proposição de indicadores. Revista Eletrônica de Estratégia \& Negócios, Florianópolis, v. 4, n. 1, p. 65-87, jan./jun. 2011.

DULIPOVICI, Alina; ROBEY, Daniel. Strategic alignment and misalignment of knowledge management systems: a social representation perspective. Journal of Management Information System, London, v. 29, n. 4, p. 103-126, 2013.

DUTOT, Vincent; BERGERON, François; RAYMOND, Louis. Information management for the internationalization of SMEs: an exploratory study based on a strategic alignment perspective. International Journal of Information Management, Amsterdam, v. 34, n. 5, p. 672-681, 2014.

EDWARDS, Barbara A. Chief executive officer behavior: the catalyst for strategic alignment. International Journal of Value-Based Management, Cham, v. 13, n. 1, p. 47-54, 2000.

GĘBCZYŃSKA, A. Strategy implementation efficiency on the process level. Business Process Management Journal, Bingley, v. 22, n. 6, p. 1079-1098, 2016.

HÅKONSSON, D. D.; BURTON, R. M.; OBEL, B.; LAURIDSEN, J. T. Strategy implementation requires the right executive style: evidence from Danish SMEs. Long Range Planning, Amsterdam, v. .45, n. 2-3, p. 182208, Apr.-June 2012.

HALTER, Judith M. A strategic approach to corporate communication: an analytic creating strategic alignment and measuring results. 2015. 317 f. Thesis (Doctor of Professional Studies)-University of Southern Queensland, Queensland, 2015.

HEIDE, M.; GRONHAUG, K.; JOHANNESSEN, S. Exploring barriers to the successful implementation of a formulated strategy. Scandinavian Journal of Management, v. 18, n. 2, p. 217-231, 2002.

HENDERSON, John C.; VENKATRAMAN, N. Strategic alignment: leveraging information technology for transforming organizations. IBM Systems Journal, Armonk, v. 32, n. 1, p. 4-16, 1993.

HERHAUSEN, D; EGGER, T; ORAL, C. Auditing marketing strategy implementation success. Marketing Review St. Gallen, Dordrecht, v. 31, n. 3, p. 55-65, 2014.

ISAL, Yugo K.; PIKARTI, Gayuh P.; HIDAYANTO, Achmad N.; PUTRA, Edson Y. Analysis of IT infrastructure flexibility impacts on IT-Business strategic alignment. Journal of Industrial Engineering and Management, Barcelona, v. 9, n. 3, p. 657-683, 2016.

KAPLAN, Robert S.; NORTON, David P. Alignment: using the balanced scorecard to create corporate synergies. Boston: HBS Press, 2006.

KAPLAN, Robert S.; NORTON, David P. Strategy maps: converting intangible assets into tangible outcomes. Boston: HBS Press, 2004.

KAPLAN, Robert S.; NORTON, David P. The balanced scorecard: translating strategy into action. Boston, HBS Press, 1996.

KAPLAN, Robert S.; NORTON, David P. The office of strategy management. Boston: HBS Press, 2005. 
KAPLAN, Robert S.; NORTON, David P. The strategy-focused organization: how balanced scorecard companies thrive in the new business environment. Boston: HBS Press, 2000.

KARIM, A.; ARIF-UZ-ZAMAN, K. A methodology for effective implementation of lean strategies and its performance evaluation in manufacturing organizations. Business Process Management Journal, v. 19, n. 1, p. 169-196, 01 Feb. 2013.

KAZUO, Ohashi. Liver and islet tissue engineering based on strategic alignment of parenchymal cells. Organ Biology, Tokyo, v. 20, n. 2, p. 192-199, 2013.

LAWRIE, Gavin; ABDULLAH, Nur A.; BRAGG, Christopher; VARLET, Guillaume. Multi-level strategic alignment within a complex organisation, Journal of Modelling in Management, Bingley, v. 11, n. 4, p. 889910. 2016.

LOCKAMY III, Archie; SMITH, Wilbur I. A strategic alignment approach for effective business process reengineering: linking strategy, processes and customers for competitive advantage. International Journal of Production Economics, Tallahassee, v. 50, p. 141-153, 1997.

LUFTMAN, J. N.; LEWIS, P. R.; OLDACH, S. H. Transforming the enterprise: The alignment of business and information technology strategies. IBM Systems Journal, Armonk, v. 32, n. 1, p. 198-221, 1993.

MACARTHUR, John B.; BROST, Mike J.; DOUECK, Bruce. Strategic alignment and systems control of processes: the case of JEA. Management Accounting Quarterly, Montvale, v. 5, n. 4, p. 11-24, Summer 2004.

MADERO GOMEZ, Sergio M.; BARBOZA, Gustavo A. Interrelación de la cultura, flexibilidad laboral, alineación estratégica, innovación y rendimiento empresarial. Contaduría y Administración, México, v. 60, n. XX, p. 735-756, 2015.

MILES, Raymond E.; SNOW, Charles C.; MEYER, Alan D.; COLEMAN JR, Henry J. Organizational strategy, structure, and process. The Academy of Management Review, New York, v. 3, n. 3, p. 546-562, Jul. 1978.

MONTEIRO DE BARROS, Luís A. Alinhamento estratégico. 2007. 159 f. Tese (Doutorado em Administração). Faculdade de Economia e Administração. Universidade de São Paulo, São Paulo, 2007.

OMONDI, M. P.; OMBUI, K.; MUNGATU, J. Factors affecting effective strategy implementation for attainment of Millennium Development Goal 5 by international reproductive health non-governmental organizations in Kenya. The TQM Journal, Bingley, v. 25, n. 5, p. 507-519, 2013.

PELLA, D. A.; SUMARWAN, U.; DARYANTO, A.; KIRBRANDOKO. Factors affecting poor strategy implementation. Gadjah Mada International Journal of Business, Yogyakarta, v. 15, n. 2, p .183-204, 01 June 2013.

PETT, Jason. Strategic alignment: internal audit functions can follow four steps toward greater involvement in strategic initiatives. Internal Auditor, Lake Mary, v. 72, n. 3 p. 59-63, June 2015.

PRIETO, V. C.; CARVALHO, M. M. Fatores chave para o alinhamento estratégico vertical: Survey com executivos brasileiros. Production, São Paulo, v. 26, n. 3, p. 626-641, jul./set. 2016.

RASHIDIRAD, Mona; SOLTANI, Ebrahim; SYED, Jawad. Strategic alignment between competitive strategy and dynamic capability. Strategic Change, Hoboken, v. 22, n. (3-4), p. 213-224, May 2013.

RAYMOND, Louis; CROTEAU, Anne-Marie. Manufacturing strategy and business strategy. IEEE Transactions on Engineering Management, Piscataway, v. 56, n. 2, p. 192-202, 2009.

SABHERWAL, Rajiv; CHAN, Yolande E. Alignment between business and IS strategies. Information Systems Research, Linthicum, v. 12, n. 1, p. 11-33, Mar. 2001. 
SARDANA, Deepak; TERZIOVSKI, Mile; GUPTA, Narain. The impact of strategic alignment and responsiveness to market on manufacturing firm's performance. International Journal of Production Economics, Amsterdam, v. 177, p. 131-138, July 2016.

SENRA, Luciana Xavier; LOURENÇO, Lélio Moura. A importância da revisão sistemática na pesquisa científica. In: BAPTISTA, Makilim Nunes; CAMPOS, Dinael de (Orgs.). Metodologias de pesquisa em ciências: análises quantitativa e qualitativa. 2. ed. Rio de Janeiro: LTC, 2016. p. 176-190.

SILVESTRO, Rhian; SILVESTRO, Claudio. New service design in the NHS: an evaluation of the strategic alignment of NHS direct. International Journal of Operations \& Production Management, Bingley, v. 23, n. 3-4, p. 401-417, Mar-Apr. 2003.

SRIVASTAVA, A. K.; SUSHIL Modelling organizational and information systems for effective strategy execution. Journal of Enterprise Information Management, Bingley, v. 28, n. 4, p. 556-578, 2015.

STROHHECKER, J. Factors influencing strategy implementation decisions: an evaluation of a balanced scorecard cockpit, intelligence, and knowledge. Journal of Management Control, Cham, v. 27, n. 1, p. 89119, 2016.

VENKATRAMAN, N. The concept of fit in strategy research: toward verbal and statistical correspondence (working paper revising and expanding the Academy of Management Best Paper Proceedings version published in 1987). Cambridge: MIT-Alfred P. Sloan School of Management, June 1988.

VENKATRAMAN, N.; CAMILLUS, John C. Exploring the concept of "fit" in strategic management. The Academy of Management Review, Briarcliff Manor, v. 9, n. 3, p. 513-525, Jul. 1984.

VERGARA, Sylvia Constant. Projetos e relatórios de pesquisa em administração. 16. ed. São Paulo: Atlas, 2016.

VILLA GONZÁLEZ DEL PINO, Eulalia M.; PONS MURGUÍA, Ramón Á.; BERMÚDEZ VILLA, Yanko. El alineamiento estratégico y la calidad de la gestión en las universidades. Prospect, Barranquilla, v. 12, n. 1, p. 21-29, enero-jun. 2014

WUNDER, Thomas. New strategy alignment in multinational corporations. Strategic Finance, Montvale, v. 87, n. 5, p. 35-41, Nov. 2005.

ZAKERY, Amir; AFRAZEH, Abbas; DUMAY, John. Analysing and improving the strategic alignment of firms' resource dynamics. Journal of Intellectual Capital, Bingley, v. 18, n. 1, p. 217-240, 2017. 